NBER WORKING PAPER SERIES

\title{
IS THE PUBLIC INVESTMENT MULTIPLIER HIGHER IN DEVELOPING COUNTRIES? AN EMPIRICAL INVESTIGATION
}

\author{
Alejandro Izquierdo \\ Ruy E. Lama \\ Juan Pablo Medina \\ Jorge P. Puig \\ Daniel Riera-Crichton \\ Carlos A. Vegh \\ Guillermo Vuletin \\ Working Paper 26478 \\ http://www.nber.org/papers/w26478 \\ NATIONAL BUREAU OF ECONOMIC RESEARCH \\ 1050 Massachusetts Avenue \\ Cambridge, MA 02138 \\ November 2019
}

We would like to thank Daniel Artana, Leopoldo Avellan, Andy Berg, Roberto Fattal, Juan Hernandez, Julian Messina, Andrew Powell, Tomas Serebrisky, Luis Serven, Ernesto Stein, Diego Vera-Cossio, and seminar participants at the Argentine Economic Association Annual Meetings (Universidad Nacional de La Plata, Argentina), Central Bank of Argentina, George Washington University, International Monetary Fund, Inter-American Development Bank, Jornadas Internacionales de Finanzas Públicas (Universidad Nacional de Cordoba, Argentina), LACEA Meetings (Ecuador), and World Bank for helpful comments and discussions. We are also grateful to María Teresa Balestrini, José Andrée Camarena Fonseca, Diego Friedheim, Luis Morano, Lucila Venturi Grosso, and Hongrui Zhang for excellent research assistance. The views expressed herein are those of the authors and do not necessarily reflect the views of the National Bureau of Economic Research.

NBER working papers are circulated for discussion and comment purposes. They have not been peer-reviewed or been subject to the review by the NBER Board of Directors that accompanies official NBER publications.

(C) 2019 by Alejandro Izquierdo, Ruy E. Lama, Juan Pablo Medina, Jorge P. Puig, Daniel RieraCrichton, Carlos A. Vegh, and Guillermo Vuletin. All rights reserved. Short sections of text, not to exceed two paragraphs, may be quoted without explicit permission provided that full credit, including $\odot$ notice, is given to the source. 
Is the Public Investment Multiplier Higher in Developing Countries? An Empirical Investigation Alejandro Izquierdo, Ruy E. Lama, Juan Pablo Medina, Jorge P. Puig, Daniel Riera-Crichton, Carlos A. Vegh, and Guillermo Vuletin

NBER Working Paper No. 26478

November 2019

JEL No. E22,E32,E62

\section{ABSTRACT}

Over the last decade, empirical studies analyzing macroeconomic conditions that may affect the size of government spending multipliers have flourished. Yet, in spite of their obvious public policy importance, little is known about public investment multipliers. In particular, the clear theoretical implication that public investment multipliers should be higher (lower) the lower (higher) is the initial stock of public capital has not, to the best of our knowledge, been tested. This paper tackles this empirical challenge and finds robust evidence in favor of the above hypothesis: countries with a low initial stock of public capital (as a proportion of GDP) have significantly higher public investment multipliers than countries with a high initial stock of public capital. This key finding seems robust to the sample (European countries, U.S. states, and Argentine provinces) and identification method (Blanchard-Perotti, forecast errors, and instrumental variables). Our results thus suggest that public investment in developing countries would carry high returns.

Alejandro Izquierdo

Inter-American Development Bank

1300 New York Ave, N. W.

Washington, D. C., 20577

alejandroi@iadb.org

Ruy E. Lama

International Monetary Fund

700 19th Street, NW

Washington, DC 20431

rlama@imf.org

Juan Pablo Medina

Universidad Adolfo Ibañez

Diagonal Las Torres 2640

Santiago

Chile

jp.medina.guzman@gmail.com

Jorge P. Puig

FCE-Universidad Nacional de La Plata

Calle 6 \#777

La Plata, 1900

Argentina

jorgeppuig@gmail.com

\author{
Daniel Riera-Crichton \\ The World Bank \\ 1818 H St NW \\ Washington, DC 20433 \\ drieracr@bates.edu \\ Carlos A. Vegh \\ School of Advanced International Studies (SAIS) \\ Johns Hopkins University \\ 1717 Massachusetts Avenue, NW \\ Washington, DC 20036 \\ and NBER \\ cvegh1@jhu.edu \\ Guillermo Vuletin \\ The World Bank \\ 1818 H Street NW \\ Washington, DC 20433 \\ gvuletin@worldbank.org
}




\section{Introduction}

Ever since the Global Financial Crisis, there has been an explosion of studies analyzing the macroeconomic effects of government spending. In particular - and inspired by familiar macroeconomic theory - a growing literature has focused on how different macroeconomic factors may affect the size of government spending multipliers. For example, a consensus is building around the idea that the size of the government spending multiplier depends on (i) the state of the economy, with multipliers being larger in recessions than in expansions (e.g., Auerbach and Gorodnichenko, 2012 and 2013; Riera-Crichton, Vegh, and Vuletin, 2015); (ii) the exchange rate regime, with multipliers being larger under fixed regimes (e.g., Ilzetzki, Mendoza, and Vegh, 2013); (iii) the degree of indebtness, with multipliers being larger when debt is low (e.g., Ilzetzki, Mendoza, and Vegh, 2013; Huidrom et al., 2019); (iv) the degree of accommodation of monetary policy, with multipliers being larger when monetary policy is loose and/or close to the zero lower bound (Christiano, Eichenbaum, and Rebelo, 2011; Coenen, Straub, and Trabandt, 2013); and (v) the degree of openness of the economy, with multipliers being smaller in economies more open to trade (e.g., Ilzetzki, Mendoza, and Vegh, 2013; Gonzalez-Garcia, Lemus, and Mrkaic, 2013).

Interestingly, since most studies focus either on primary spending or government consumption, there does not seem to be much evidence on multipliers for public investment. ${ }^{1}$ What do we know about public investment multipliers? Early theoretical work by Aschauer (1989a, 1989b) and Baxter and King (1993) and more recent empirical evidence (e.g., Auerbach and Gorodnichenko, 2013; Leduc and Wilson, 2012; Eden and Kraay, 2014; Calderon, Moral-Benito, and Serven, 2015; Furceri and Li, 2017) have found that the public investment multiplier can be quite large, especially when compared to the government consumption multiplier. The typical argument is that, unlike government consumption, public investment directly improves the economy's productive capacity by increasing the marginal product of private capital and labor. As time progresses, this generates positive effects both on private investment and private consumption.

It is essential to learn more about the determinants of the size of the public investment multiplier, especially in light of current concerns about how to raise economic growth, increase

\footnotetext{
${ }^{1}$ Recall that, by definition, government spending is the sum of primary spending and interest payments and, in turn, primary spending comprises current primary spending and public investment. Finally, current primary spending comprises government consumption and transfers. When referring to different types of government spending, we will use the terms public and government interchangeably.
} 
productivity, and reinvigorate the role of the private sector which, in turn, has triggered a major policy push around the world for more public investment/infrastructure. In particular, there has been great interest in better understanding the effect of lack of efficiency on the size of the public investment multiplier, broadly defined as cost overruns, implementation delays, institutional weaknesses, and wasteful use of resources (including corruption). The evidence clearly suggests that the output effect of public investment falls when efficiency is low (Leeper, Walker, and Yang, 2010; Cavallo and Daude, 2011; Leduc and Wilson, 2012; Furceri and Li, 2017; Izquierdo, Pessino, and Vuletin, 2018).

In this context, and motivated particularly by the large gaps in public investment and infrastructure in the developing world, this paper asks a natural and relevant question: does the size of the public investment multiplier depend on the initial stock of public capital? From a theoretical point of view, the answer is simple. Standard neoclassical fiscal policy growth models (like the classic contribution of Baxter and King, 1993) would predict that the lower the initial stock of public capital, the larger the output effects of increasing public investment. Specifically, when the initial stock of public capital is low, the marginal productivity of an additional unit of public investment is large which, aided also by additional private investment, will lead to higher public investment multipliers. Conversely, when the initial stock of public capital is high, the impact of additional public investment should be low. Hence, in the case of developing countries (low stock of public capital), public investment multipliers should be higher. But does this basic theoretical result hold in practice ${ }^{2}$ We tackle this empirical challenge and find, using different samples, levels of government, and identification strategies, that the initial stock of public capital indeed matters for the size of the public investment multiplier (and in the direction suggested by the theory).

The paper proceeds as follows. Section 2 carries out the empirical analysis using a sample of 31 European countries relying on Blanchard and Perotti's (2002) identification strategy. Section 3 focuses on U.S. states using government spending forecast errors to identify spending innovations (as in Auerbach and Gorodnichenko, 2012 and 2013). Section 4 resorts to data from Argentine provinces and an instrumental variables approach. Section 5 provides further support for our findings by comparing international evidence in 17 country-specific external studies (for which we were able to find public investment multiplier calculations) with our calibrated estimates. Section 6 closes the paper with some final thoughts about the relevance of our empirical findings.

\footnotetext{
${ }^{2}$ Of course, economics is full of "obvious" theoretical results that do not hold in practice. An example, and closely related to our question, is the so-called Lucas (1990) paradox: why does not capital flight from rich countries (with low marginal productivity of capital) to poor countries (with high marginal productivity of capital)? Possible explanations are offered by, among others, Tornell and Velasco (1992) and Alfaro et al. (2008).
} 


\section{Empirical evidence from European countries}

This section estimates three different types of government spending multipliers using unbalanced non-interpolated quarterly data for the period 1987:Q1-2014:Q4 for 31 European countries. $^{3}$

\subsection{Identification strategy}

In terms of the empirical strategy for the identification of exogenous government spending shocks, we follow the well-known Blanchard and Perotti (2002) methodology that imposes timing restrictions by assuming that (i) government spending changes are allowed to contemporaneously affect economic activity (i.e., within the quarter), and (ii) it takes the government at least one quarter to respond to developments in the state of the economy.

We estimate the effect of innovations of government spending on economic growth using the single-equation approach proposed by Jorda (2005) and Stock and Watson (2007), which is based on linear local projections (LP). The use of LP provides several advantages over the traditional structural vector autoregressive (SVAR) methodology. Specifically, LP (i) can be estimated by single-regression techniques (least-squares dummy variables, LSDV, in our case), (ii) are more robust to potential misspecifications, and (iii) can easily accommodate highly non-linear and flexible specifications that may be impractical in a multivariate SVAR context (a feature that proves to be crucial in this paper). ${ }^{4}$

In our basic linear specification, the cumulative response of output growth at the horizon $h$ is estimated based on the following regression:

$$
\Delta y_{i, t+h}=\alpha_{i, h}+\beta_{h} \Delta g_{i, t}+\lambda_{h}(L) \Delta y_{i, t-1}+\psi_{h}(L) \Delta g_{i, t-1}+\varrho_{h} T_{h}+v_{h} T_{h}^{2}+\mu_{i, t, h},
$$

\footnotetext{
${ }^{3}$ As discussed in detail in Ilzetzki, Mendoza, and Vegh (2013), relying on interpolated quarterly data creates serious problems associated with measurement errors. The list of countries comprises Belgium, Bulgaria, Czech Republic, Denmark, Germany, Estonia, Ireland, Greece, Spain, France, Croatia, Italy, Cyprus, Latvia, Lithuania, Luxembourg, Hungary, Malta, Netherlands, Austria, Poland, Portugal, Romania, Slovenia, Slovakia, Finland, Sweden, United Kingdom, Iceland, Norway, and Switzerland. See Appendix 1 for a detailed description of data definitions, sources, and time coverage.

${ }^{4}$ We should note that Jorda's LP method does not consistently dominate the standard SVAR method for calculating impulse responses of endogenous variables with contemporaneous effects. Since Jorda's LP does not impose any restrictions linking the impulse responses at $h$ and $h+1$, estimates can display an erratic behavior due to the loss of efficiency. Additionally, as the horizon increases, one loses observations from the end of the sample. Finally, the impulse responses sometimes display oscillations at longer horizons. Comparing Jorda's LP to a standard SVAR and a dynamic simulation, Ramey (2016) finds that the results are qualitatively similar for the first 16 quarters. For longer horizons, however, Jorda's LP method tends to produce statistically significant oscillations not observed in the other two methods. For these reasons, and to err on the safe side, we report estimates up to 8 quarters after public spending shocks. Similar results would obtain if we reported estimates up to 12 quarters after fiscal and GDP shocks.
} 
where subscripts $i$ and $t$ denote country and time (year-quarter), respectively; $\alpha_{i}$ is the country fixed effect; $T$ and $T^{2}$ are the linear and quadratic trends; $y$ and $g$ are, respectively, the logarithms of real GDP and, depending on the case, real primary spending, real government consumption, or real public investment; $\Delta y_{i, t+h}\left(\equiv y_{i, t+h}-y_{i, t-1}\right)$ represents the accumulated output growth from $t-1$ to $t+h$; and $\mu$ is the error term. ${ }^{5},{ }^{6}$ To report the usual government multiplier, which measures the effect of a $\$ 1$ change in government spending on the level of GDP, we multiply (as is typical in this literature) the coefficients $\beta_{h}$ by the average ratio of GDP to government spending.

To allow for the size of the public investment multiplier to depend upon the ratio of the initial stock of public capital to GDP, we modify our linear specification (1) for the case of public investment as follows:

$$
\begin{aligned}
\Delta y_{i, t+h}= & \alpha_{i, h}+\beta_{1, h} \Delta g_{i, t}+\beta_{2, h}\left(\Delta g_{i, t} \cdot s t o c k_{i, 0}\right)+ \\
& +\lambda_{h}(L) \Delta y_{i, t-1}+\psi_{h}(L) \Delta g i_{i, t-1}+\varrho_{h} T_{h}+v_{h} T_{h}^{2}+\mu_{i, t, h}
\end{aligned}
$$

where the only difference is the interaction term between the public investment shock and stock $_{i, 0}$ (the ratio of the initial stock of public capital to GDP, expressed in logarithms). To avoid endogeneity problems, we use the ratio observed during the period 1980-1985 for most European countries. ${ }^{7,8}$ Since, by construction, stock $k_{i, 0}$ is constant for each country, the term associated with the ratio of the initial stock of public capital to GDP is not included in specification (2) for control purposes because it is absorbed by the country fixed effect. We now use this empirical methodology to estimate the fiscal multipliers, which will be reported, as is common in the literature, with one-standard-error bands.

\subsection{Primary spending versus public investment multipliers}

Before turning to public investment multipliers, we first estimate, as a useful benchmark, the primary spending multiplier (as has been typically the case in the fiscal multiplier literature). Panel A in Figure 1 shows that, on impact, the primary spending multiplier is $0.13(t=4.5)$

\footnotetext{
${ }^{5}$ We include linear and quadratic trends as in Owyang, Ramey, and Zubairy (2013) and Riera-Crichton, Vegh, and Vuletin (2015). In all of our regression analyses, we use robust Driscoll and Kraay (1998) standard errors to correct for potential heteroskedasticity, autocorrelation in the lags, and error correlation across panels. We use four lags (i.e., $L=4$ ). Our results for the case of eight and twelve lags remain almost the same as in the four-quarter lag specification. Figures showing the multipliers for the eight- and twelve-quarter lags estimations are not shown for the sake of brevity.

${ }^{6}$ For the purposes of this paper, and as is common in the literature, we will use data on current primary spending as a proxy for public consumption.

${ }^{7}$ See Apendix 1 for a detailed description of data definitions, sources, and time coverage.

${ }^{8}$ If the initial stock of public capital over GDP ratio is allowed to change over time for estimation purposes (e.g., by using the ratio in $t-1$ ), similar results are obtained. Results are not shown for the sake of brevity.
} 
and becomes larger with longer time horizons until reaching $0.25(t=1.3)$ after two years of the spending shock. These low multipliers are in line with previous studies focusing on industrial countries (e.g., Auerbach and Gorodnichenko, 2012; Alesina, Favero, and Giavazzi, 2015).

We now focus on the mechanisms involved by evaluating the response of aggregate components of GDP. These low multipliers are driven by the tepid response of private consumption (Panel B in Figure 1) and no response of private investment (Panel C). In fact, private investment does not respond to a primary spending shock at any time horizon. It is worth noting that the results for government consumption multipliers (not shown for the sake of brevity) are virtually identical to those for primary spending multipliers. ${ }^{9}$

\section{FIGURE 1}

We now turn to public investment multipliers. Panels D, E, and F in Figure 1 are analogous to Panels A, B, and C, respectively, but for public investment multipliers (rather than primary spending multipliers). The public investment multiplier grows over time, reaching larger and more lasting effects. Panel D in Figure 1 shows that, on impact, the public investment multiplier is $0.15(t=2.5)$, which is virtually identical to the primary spending multiplier shown in Panel A (0.13). However, the public investment multiplier becomes larger with longer time horizons until reaching $0.80(t=3.3)$ after two years of the public investment shock. In fact, we cannot reject the null hypothesis that the multiplier equals one. Moreover, this medium-term multiplier is more than 3 times as large as the one associated with a primary spending shock (i.e., 0.80 in Panel D compared to 0.25 in Panel A). This reflects the stronger response of both private consumption (Panel E) and private investment (Panel F). As expected, the public investment multiplier involves positive spillovers of productive public capital on private capital. When public capital is productive, public investment increases the marginal productivity of private capital and labor which, in turn, creates the incentives for expanding private investment. In other words, a public investment shock generates a crowding-in effect of private investment.

\subsection{Does the initial stock of public capital matter?}

As discussed above, theory tells us that the size of the public investment multiplier should depend upon the initial stock of public capital. Specifically, the public investment multiplier should depend negatively on the ratio of public capital to GDP. We now test this hypothesis.

\footnotetext{
${ }^{9}$ This is not surprising since current primary spending represents about 93 percent of primary spending for this group of European countries.
} 
Interestingly, and importantly for identification considerations, Figure 2 shows the large variability of the ratio of the initial stock of public capital to GDP across the European countries in the sample (with a coefficient of variation of 0.55 ). While the median ratio is 0.63 , the ratio is about 0.25 for some countries (including Hungary, Latvia, Malta, and Greece) but reaches values above one for other countries (Romania, Luxembourg, Cyprus, and Denmark).

\section{FIGURE 2}

Turning now to the estimates of the multiplier, Figure 3 shows that the size of the initial stock of public capital certainly matters. Specifically, Figure 3 shows the results of estimating regression (2) and evaluating the size of the public investment multiplier for a high ratio (95th percentile or 1.33 ratio) and a low ratio (5th percentile or 0.16 ratio) of the initial stock of public capital to GDP. Panels A, B, and C in Figure 3 show the multipliers associated with a public investment shock - evaluated at the high ratio - on GDP, private consumption, and private investment, respectively. Panels D, E, and F show the same multipliers but evaluated at the low ratio. On impact, the multipliers are quite similar (and small in size) regardless of the ratio of the initial stock of public capital to GDP (0.25 in Panel A and 0.18 in Panel D). As the horizon becomes larger, however, the difference between the two multipliers grows markedly. For the case of the high ratio, the size of the multiplier remains small and statistically weak, reaching $0.15(t=0.2)$ after two years of the public investment shock. In sharp contrast, when starting with a low ratio, the multiplier becomes larger with longer time horizons until reaching $2.15(t=2.1)$ after two years of the public investment shock. In fact, we cannot reject the null hypothesis that this multiplier is larger than one statistically speaking. This reflects the stronger response of both private investment (Panel F) and private consumption (Panel E).

\section{FIGURE 3}

Focusing on the effect after two years of the public investment shock, Figure 4 illustrates the crucial role played by the ratio of the initial stock of public capital to GDP on the size of the public investment multiplier by plotting the latter as a function of the former. While the multiplier is statistically zero at high levels of the ratio of the initial stock of public capital to GDP ratio (i.e., higher than 1), it becomes statistically significant and increasingly positive with lower ratios. Moreover, for sufficiently low levels of the ratio (i.e., lower than 0.25), the public investment multiplier becomes larger than one. In other words, the increase (fall) of GDP associated with increasing (reducing) public investment by $\$ 1$ tends to be zero for 
high levels of the ratio of the initial stock of public capital to GDP and becomes larger as the initial ratio decreases.

\section{FIGURE 4}

These findings have important policy implications given that the ratio of the initial stock of public capital to GDP varies greatly across countries (and over time) and thus so will the size of the public investment multipliers. As an illustration, Figure 5 shows the implied public investment multipliers for our European sample for the ratio of the initial stock of public capital to GDP ratio prevailing in 1990 (Panel A) and 2014 (Panel B). Interestingly, between 1990 and 2014, the public investment multiplier fell the most in Southern economies and new members from the Eastern bloc. This came about because of important rises in the stock of public capital, following efforts to increase the stock of infrastructure and other productive investments in least-favored regions as a result of the European Regional Development Fund (ERDF) and the Cohesion Fund (CF).

\section{FIGURE 5}

\subsection{An out-of-sample application}

We now conduct an out-of-sample exercise (which, as such, should be taken with a grain of salt) with the purpose of helping contextualize our findings for two countries for which we will also estimate the public investment multipliers in subsequent sections (relying on alternative identification strategies and datasets). Using the ratio of the initial stock of public capital to GDP for the U.S., the estimated public investment multipliers for 1960 and 2015 are, respectively, 0.4 (and statistically zero) and 0.85 (and statistically not different from one). This reflects the steady fall in the ratio of public capital to GDP between 1960 (ratio of 1.04) and 2015 (0.64).

In the case of Argentina, the estimated public investment multipliers for 1960 and 2015 are 1.9 (and statistically larger than one) and 1.4 (and statistically equal to one), respectively. Why? Because of the almost doubling of the ratio of public capital to GDP from 0.20 in 1960 to 0.35 in 2015. In other words, both countries used to have a much larger difference in their public investment multipliers (with the U.S. having a statistically zero multiplier and Argentina having an statistically larger than one multiplier) due to the fact that the ratio of public capital to GDP was more than five times as high in the U.S. as in Argentina. Interestingly, as this ratio tended to "converge" (the previous 5-fold difference shrank to about 2 -fold), both countries have also tended to "converge" in the size of their public investment multipliers (in both cases statistically positive and equal to one). As will be shown below, 
these findings will be strongly supported when relying on alternative identification strategies and datasets for U.S. states and Argentine provinces.

\subsection{The role of spending efficiency}

As discussed in the Introduction, there is a recent and growing literature showing that efficiency, broadly defined as including, among others, cost overruns, implementation delays, institutional weakness, corruption, and wasteful use of resources - also seems to matter. In particular, the effect of public investment on output falls when efficiency is low (Leeper, Walker, and Yang, 2010; Cavallo and Daude, 2011; Leduc and Wilson, 2012; Furceri and Li, 2017; Izquierdo, Pessino, and Vuletin, 2018). This subsection shows that while efficiency matters, it does not affect our novel insight regarding the initial stock of public capital. ${ }^{10}$

For this purpose, we extend our non-linear specification (2) to control for the role of spending efficiency as follows:

$$
\begin{aligned}
\Delta y_{i, t+h}= & \alpha_{i, h}+\beta_{1, h} \Delta g_{i, t}+\beta_{2, h}\left(\Delta g_{i, t} \cdot \text { stock }_{i, 0}\right)+\beta_{3, h}\left(\Delta g_{i, t} \cdot \text { efficiency }_{i}\right)+ \\
& +\lambda_{h}(L) \Delta y_{i, t-1}+\psi_{h}(L) \Delta g i_{i, t-1}+\varrho_{h} T_{h}+v_{h} T_{h}^{2}+\mu_{i, t, h}
\end{aligned}
$$

where the only difference is, with respect to specification (2), the interaction term between the public investment shock and efficiency, which proxies for spending efficiency in each country. In particular, and as detailed in data Appendix 1, efficiency is obtained as the first principal component of a wide set of indicators (36 to be specific) of institutional quality as well as indicators of the quality of infrastructure, education, and health. ${ }^{11}$ These indicators are taken from the Global Competitiveness report, published by the World Economic Forum and covering 142 countries for the period 2004-2014. ${ }^{12}$ Each quality indicator varies between 1 (worst) and 7 (best). The variable efficiency is computed as the average of the abovementioned first principal component for each country. It effectively varies, for the global sample, between 2.5 and 6 and, for the European sample used here, between 3.5 and 6 .

Panel A in Figure 6 shows that, like in previous studies, efficiency arguments matter.

\footnotetext{
${ }^{10}$ Berg et al. (2019) analyze the role of public investment efficiency in a neoclassical growth model, and show that, in developing countries, the public investment multiplier might be high because the effect of having a high marginal product of public capital (reflecting the scarcity of public investment) may offset the low efficiency associated with expanding public infrastructure.

${ }^{11}$ The first principal component explains about 65 percent of the underlying comovement of the 36 selected indicators. Several combinations of these 36 indicators have been used as robustness checks. Results remain virtually unchanged and are not reported for the sake of brevity.

${ }^{12}$ This report covers 110 variables, of which two thirds come from the Executive Opinion Survey, and the remaining third comes from publicly available sources such as the United Nations. The Executive Opinion Survey is a survey of a representative sample of business leaders in their respective countries. The number of respondent has increased every year and is currently just over 13,500 in 142 countries.
} 
While for low levels of efficiency, the size of the public investment multiplier tends to be zero (statistically speaking), the size of the multiplier becomes larger for higher levels of efficiency. More importantly for the purposes of our contribution, Panel B in Figure 6 shows that our novel insight regarding the role of the initial stock of public capital in determining the size of the public investment multiplier remains virtually unaffected after controlling for efficiency. ${ }^{13,14}$

FIGURE 6

\section{Empirical evidence for U.S. states}

This section estimates state government multipliers using balanced annual data for the period 1987-2016 for U.S. states. ${ }^{15,16}$ It is worth noting that primary government spending by U.S. states represents, on average, about 40 percent of general primary spending, thus playing a substantial role in the fiscal policy landscape.

\subsection{Identification strategy}

In terms of the empirical strategy for the identification of exogenous government spending shocks, we follow the so-called government spending forecast error approach, which uses the difference between actual (i.e., ex-post) and anticipated (i.e., ex-ante) series in government spending as a proxy for innovations in government spending. As discussed in detail in Auerbach and Gorodnichenko $(2012,2013)$, this approach provides a convenient way to identify

\footnotetext{
${ }^{13}$ It is worth noting that, using a global sample of 128 countries, we cannot reject the null that the correlation between variables stock $_{i, 0}$ and efficiency $i$ is statistically zero.

${ }^{14}$ In terms of the importance of macroeconomic factors potentially affecting the size of the spending multiplier discussed in the Introduction, it is worth noting that, using a global sample, stock ${ }_{i, 0}$ is not statistically correlated with (i) exchange rate regimes (from Ilzetzki, Reinhart, and Rogoff, 2017), (ii) trade openness (defined as imports plus exports over GDP from WDI), (iii) capital account openness (from Chinn and Ito, 2006), (iv) real PPP GDP per capita (from PWT), (v) public debt over GDP (from WDI and Kose et al., 2017), (vi) external debt over GDP (from WEO and Huidrom et al., 2019), and (vii) cyclicality of government spending (from Frankel, Vegh, and Vuletin, 2013). For variables (i) to (iv) we use, in line with stock $k_{i, 0}$, the average for the period 1980-1985. For variables (v), (vi), and (vii) the coverage is 1990-1995, 19901995, and 1960-1985, respectively. Due to data availability, the number of countries covered varies between 95 and 133 depending on the variable under consideration. The same is true (that these variables are not related to $s \mathrm{c}_{\mathrm{i}, 0}$ ) when solely focusing on our European sample. Moreover, when replicating figures (for all these macroeconomic variables) similar to that of Panel B in Figure 6, the effect of the initial stock of public capital remains virtually unchanged in all cases. In other words, there is robust evidence that these other macroeconomic determinants are not, empirically speaking, behind the role of the initial stock of public capital. Results are not shown for the sake of brevity.

${ }^{15} \mathrm{As}$ is typical in the public finance literature that focuses on fiscal issues in U.S. states, we exclude the state of Hawaii due to its highly unusual fiscal structure and Alaska because of its extreme dependence on oil revenue (e.g., Sorensen, $\mathrm{Wu}$, and Yosha, 2001).

${ }^{16}$ See Appendix 2 for a detailed description of data definitions and sources.
} 
unanticipated government spending, which enables a proper estimation of government spending multipliers.

In our basic linear specification, the response of output growth is estimated based on the following regression:

$$
\Delta y_{i, t}=\alpha_{i}+\beta \Delta \ln G_{i, t}^{F E}+\lambda(L) \Delta y_{i, t-1}+\psi(L) \Delta g_{i, t-1}+\varrho T+v T^{2}+\mu_{i, t}
$$

where subscripts $i$ and $t$ denote state and year, respectively; $\alpha_{i}$ is the state fixed effect; $T$ and $T^{2}$ are the linear and quadratic trends; $y$ and $g$ are the logarithms of real state GDP and real state government spending; $G_{i, t}^{F E} \equiv\left(G_{i, t}^{\text {actual }}-G_{i, t}^{\text {anticipated }}\right) / Y_{i, t}$ represents the state government spending forecast error; that is, the difference between actual (i.e., at time $t$ ) and anticipated (i.e., at time $t$ forecasted at time $t-1$ ) state government spending computed from yearly reports issued by the National Association of State Budget Officers (NASBO); and $\mu$ is the error term. ${ }^{17,18,19}$ Depending on the multiplier being estimated, real state government spending and state government spending forecast error will be based on primary spending, government consumption, or public investment. Given that government spending shocks are already divided by GDP, $\beta$ represents the usual government multiplier.

To allow the size of the public investment multiplier to depend upon the ratio of the initial stock of public capital to GDP, we modify our linear specification (4) as follows:

$$
\begin{aligned}
\Delta y_{i, t}= & \alpha_{i}+\beta_{1} \Delta \ln G_{i, t}^{F E}+\beta_{2}\left(\Delta \ln G_{i, t}^{F E} \cdot \text { stock }_{i, 0}\right)+ \\
& +\lambda(L) \Delta y_{i, t-1}+\psi(L) \Delta g_{i, t-1}+\varrho T+v T^{2}+\mu_{i, t}
\end{aligned}
$$

where the only difference is the interaction term between the public investment shock and stock $_{i, 0}$ (the ratio of the initial stock of public capital to GDP in each state, expressed in logarithms). To avoid possible endogeneity problems, we use the average ratio observed in each state during the period 1980-1985..$^{20,21}$ Since, by construction, stock $k_{i, 0}$ is constant for

\footnotetext{
${ }^{17}$ NASBO reports publish itemized state consolidated as well as anticipated public spending, by category of spending. To extract the innovation in the state public spending variable, we subtract the consolidated amount for each year, normally reported a year later, from the amount anticipated and normally reported the previous year. See, for example, Poterba (1994) who also uses this strategy for identification of fiscal shocks in U.S. states.

${ }^{18}$ In all of our regression analyses, we use robust Driscoll and Kraay (1998) standard errors to correct for potential heteroskedasticity, autocorrelation in the lags, and error correlation across panels.

${ }^{19}$ We use one lag (i.e., $L=1$ ). Our results for the case of two lags remain almost the same as in the one-year lag specification. Figures showing the multipliers for the two-year lags estimations are not shown for the sake of brevity.

${ }^{20}$ See Appendix 1 for a detailed description of data definitions and sources.

${ }^{21}$ If the ratio of the initial stock of capital to GDP is allowed to change over time for estimation purposes (e.g., by using the ratio in $t-1$ ), similar results are obtained. Results are not shown for the sake of brevity.
} 
each state, the term associated with the ratio of the initial stock of public capital to GDP is not included in specification (5) for control purposes because it is absorbed by the state fixed effect. Unfortunately, there are no long-enough time series for private consumption and private investment at the state level to test the mechanisms involved.

\subsection{Empirical results}

Figure 7 shows that the multiplier for state primary spending is quite low; specifically 0.08 $(t=1.3)$. This finding is in line with, for example, Clemens and Miran (2012) who also find state government spending multipliers statistically indistinguishable from zero. As was the case in the European sample of Section 2.2, it is worth noting that the size of the government consumption multipliers (not shown for the sake of brevity) are virtually identical to that of primary spending multipliers. ${ }^{22}$

We now turn to public investment multipliers. The public investment multiplier is much larger $0.98(t=3.0)$. In fact, we cannot reject the null hypothesis that the multiplier is equal to one. This result is in line with Coenen et al. (2012) who, relying on different DSGE models - including European Commission QUEST, International Monetary Fund GIMF, and the Board of Governors of the Federal Reserve System (both FRB-US and SIGMA) - find a multiplier of about one as well. Interestingly enough, if one used the average stock of public capital to GDP for the U.S. for the period covered in this analysis (i.e., 1987-2016), but relying on the empirical strategy and findings of the previous section (i.e., conducting an out-of-sample exercise based on the results of Section 2.3), the estimated public investment multiplier would be $0.85(t=2.4)$, very similar to that found here by using state data and the government spending forecast error approach. ${ }^{23}$

\section{FIGURE 7}

We now test whether the initial stock of public capital actually matters for the size of the public investment multiplier. Interestingly, and important for identification considerations, Figure 8 shows the large variability of the ratio of the initial stock of public capital to GDP across U.S. states, with a coefficient of variation of 0.43 .

\section{FIGURE 8}

\footnotetext{
${ }^{22}$ This is not surprising considering that current primary spending typically represents about 92 percent of primary spending for U.S. states.

${ }^{23}$ Moreover, as in the case of the public investment multiplier estimated in this section for the U.S. states $(0.98, t=3.1)$, we cannot reject the null hypothesis that this out-of-sample public investment multiplier $(0.85$, $t=2.4$ ) equals one.
} 
When evaluating the role of the ratio of the initial stock of public capital to GDP using specification (5), Figure 7 shows that the public investment multiplier associated with a high ratio, $0.51(t=2.12)$, is less than half the size of that associated with a low ratio, 1.36 $(t=4.2) .{ }^{24}$ In fact, while we cannot reject the null that the former multiplier is lower than one, we cannot reject the null that the latter multiplier is larger than one.

Figure 9 shows (like Figure 4 for the European sample of countries) the public investment multiplier as a function of the ratio of the initial public capital to GDP. While the multiplier is virtually zero at high levels of this ratio (i.e., higher than 1.9), it becomes statistically significant and increasingly positive with lower ratios. Moreover, for sufficiently low levels of this ratio (i.e., lower than 0.5), the public investment multiplier becomes larger than one. In other words, the increase (fall) of GDP associated with increasing (reducing) state public investment by $\$ 1$ tends to be zero for high levels of the ratio of initial stock of public capital to GDP in each state and becomes larger as this ratio decreases.

\section{FIGURE 9}

These findings have important policy implications given that the ratio of the initial stock of public capital to GDP varies across U.S. states (and over time) and thus so will the size of the public investment multipliers. Figure 5 shows the implied public investment multipliers for U.S. states given the stock of public capital over GDP ratio prevalent, as an example, in mid1980s (Panel A) and in 2012 (Panel B). Interestingly, in all but one U.S. state (Wyoming), the stock of public capital over GDP ratio fell, on average, more than 30 percent (from ratios averaging 1.02 in the mid-1980s to about 0.68 in 2012). As a result, the public investment multipliers have increased across the board.

\section{FIGURE 10}

In sum, this empirical evidence for U.S. states relying on the government spending forecast error approach also supports the importance of the initial stock of public capital in determining the size of the public investment multiplier. Moreover, the specific size of the public investment multiplier (as well as its evolution over time) obtained in this section matches quite well that of the previous section (when conducting an out-of-sample exercise for the U.S.). These results provide further support for our empirical findings.

\footnotetext{
${ }^{24}$ As in Section 2.3 for the European sample, we use the 5th percentile and 95th percentile to identify low and high initial stocks of public capital over GDP ratios in U.S. states, respectively.
} 


\section{Empirical evidence for Argentine provinces}

This section estimates provincial government spending multipliers using balanced annual data for the period 1964-2014 for the 23 Argentine provinces. ${ }^{25,26}$ Primary spending conducted by provinces represents, on average, about 50 percent of general primary spending, thus playing a substantial role in the fiscal policy landscape.

\subsection{Identification strategy}

In terms of the empirical strategy for the identification of exogenous government spending shocks, we follow an instrumental variables approach. Given our identification strategy, we first propose instrument(s) for primary spending and, then, for its components (government consumption and public investment).

\subsubsection{Instrumenting primary spending}

To estimate the primary spending multiplier - and, as will become clear below, given the nature of our instrumental variable approach - our basic linear specification is given by

$$
y_{i, t}^{p c}=\alpha_{i}+\beta g_{i, t}^{p c}+\lambda y_{i, t-1}^{p c}+\varrho T+v T^{2}+\mu_{i, t},
$$

where subscripts $i$ and $t$ denote province and year, respectively; $\alpha_{i}$ is the provincial fixed effect; $T$ and $T^{2}$ are the linear and quadratic trends; $y^{p c}$ and $g^{p c}$ are the logarithms of real provincial GDP per capita and real provincial primary spending per capita, respectively; and $\mu$ is the error term. ${ }^{27,28}$ To report the usual government spending multiplier, which measures the effect of a $\$ 1$ change in government spending on the level of GDP, we multiply (as is typical in this literature), regression coefficients associated with the spending shock by the average ratio of GDP to provincial government spending.

To identify exogenous provincial primary spending per capita shocks, we follow an instrumental variables approach using provincial over-representation in the Argentine National Chamber of Deputies (defined as the difference between the actual number of provincial leg-

\footnotetext{
${ }^{25} \mathrm{As}$ is typical in the public finance literature when it comes to the fiscal analysis of Argentine provinces, we exclude the Autonomous City of Buenos Aires because of the availability of only short times-series and a special treatment in terms of the Argentine federal fiscal transfer system (e.g., Porto and Sanguinetti, 2001; Vegh and Vuletin, 2015).

${ }^{26}$ See Appendix 1 for a detailed description of data definitions and sources.

${ }^{27}$ In all of our regression analyses, we use robust Driscoll and Kraay (1998) standard errors to correct for potential heteroskedasticity, autocorrelation in the lags, and error correlation across panels.

${ }^{28}$ To address possible spurious correlation concerns, we use Im, Pesaran, and Shin (2003) to tests for unit roots or stationarity in panel datasets. We reject the null hypothesis that all the panels contain a unit root.
} 
islators per capita and that based on proportional representation) as an instrument. The rationale behind this instrument relies on three key factors. First, as is typical in many federal countries, a large share (about two-thirds in the case of Argentina) of provincial primary spending is financed with federal fiscal transfers. ${ }^{29}$ Indeed, Panel A in Figure 11 shows, even after controlling for provincial fixed effects and linear and quadratic trends, a strong positive association between federal fiscal transfers per capita and provincial primary spending per capita (at a 1 percent level of significance). Second, and based on several well-established political economy arguments (e.g. Holcombe and Zardkoohi, 1981; Atlas et al., 1995 and 1997; Porto and Sanguinetti, 2001; Knight, 2008), national legislators of overrepresented jurisdictions tend to receive larger federal fiscal transfers per capita because of their bargaining power and incentives associated with greater legislative representation. In most countries, this over-representation originates, by construction, from the Senate Chamber. Interestingly, as discussed in Porto and Sanguinetti (2001) and Vegh and Vuletin (2015), in the case of Argentina such over-representation is dominated by the effect derived from the National Chamber of Deputies. ${ }^{30}$ Panel B in Figure 11 strongly supports these arguments by showing a tight positive association, even after controlling for provincial fixed effects and linear and quadratic trends, between the so-called provincial effective distortion in the Chamber of Deputies (measure obtained from Vegh and Vuletin, 2015) and federal fiscal transfers per capita (at a 1 percent level of significance). Vegh and Vuletin (2015) define provincial effective distortion in the Chamber of Deputies as the ratio between (i) absolute distortion in the Chamber of Deputies (defined as the number of national deputies per province including the provisions established in each constitutional reform and that based on the principle of proportional representation) and (ii) the respective provincial population in the year of each

\footnotetext{
${ }^{29}$ These transfers are essentially unconditional (i.e., they are not a direct function of provincial spending). About two-thirds of these transfers are ruled by a tax-sharing law dating back to 1935 (which is modified by the National Congress every ten years or so) and one-third are discretionary in nature (typically used in exchange for the support of provincial legislators in the National Congress for laws and reforms pushed by the federal government). See Porto and Sanguinetti (2001) and Vegh and Vuletin (2015) for details on the fiscal federalism structure in Argentina.

${ }^{30}$ This occurs because of two main arguments. First, and against the principle of "one person, one vote," several Constitutional amendments notoriously bolstered the over-representation in the National Chamber of Deputies. Peron's Constitutional reform of 1949 established a minimum of 2 deputies per province, regardless of the population. The military regime Constitutional reform of 1972 added one deputy per province (independently of the number of seats based on strict proportional representation). The military regime Constitutional reform of 1983 abolished the 1949 and 1972 Constitutional reforms and increased to 5 the minimum number of deputies per province. Consequently, for example, in the year 2000, a vote for the Chamber of Deputies in the province of Tierra del Fuego (the least populated province with about 0.2 percent of total population) was equivalent to about 10 votes in the province of Buenos Aires (the most populated province with about 40 percent of total population). Second, and as discussed in Porto and Sanguinetti (2001), since political power has been less concentrated in the Chamber of Deputies compared to the Senate Chamber, the Chamber of Deputies has represented the strongest constraint to passing laws, allowing Deputies to obtain much more bargaining power.
} 
constitutional reform. ${ }^{31,32}$ Third, and as discussed in Vegh and Vuletin (2015) on the basis of historical documentation, constitutional amendments regarding the number of legislators per province were driven by governance and political considerations and were not enacted in response to macroeconomic developments. Therefore, provincial over-representation in the Argentine National Chamber of Deputies offers an exogenous variation in provincial primary spending per capita (through its crucial effect on federal fiscal transfers per capita for each province). Indeed, Panel $\mathrm{C}$ in Figure 11 shows a strong positive association, even after controlling for provincial fixed effects and linear and quadratic trends, between the provincial effective distortion in the Chamber of Deputies (i.e., the proposed instrument) and provincial primary spending per capita (i.e., the instrumented variable), at a 1 percent level of significance. ${ }^{33}$

\section{FIGURE 11}

\subsubsection{Instrumenting government consumption and public investment}

To estimate the provincial government consumption and provincial public investment multipliers, we modify our linear specification (6) as follows:

$$
y_{i, t}^{p c}=\alpha_{i}+\beta^{c} g c_{i, t}^{p c}+\beta^{i} g i_{i, t}^{p c}+\lambda y_{i, t-1}^{p c}+\varrho T+v T^{2}+\mu_{i, t},
$$

where $g c^{p c}$ and $g i^{p c}$ are the logarithms of real provincial government consumption per capita and real provincial public investment per capita, respectively. Since by construction, $g_{i, t}^{p c} \equiv$ $g c_{i, t}^{p c}+g i_{i, t}^{p c}$, one could think of $g c_{i, t}^{p c}=\theta_{i, t} \cdot g_{i, t}^{p c}$ and $g i_{i, t}^{p c}=\left(1-\theta_{i, t}\right) \cdot g_{i, t}^{p c}$, where $\theta_{i, t}$ and $1-\theta_{i, t}$ measure the proportion of primary spending per capita in province $i$ in year $t$ allocated to government consumption and public investment, respectively. Taking this into account, we instrument real provincial government consumption per capita and real provincial public investment per capita using (i) the provincial effective distortion in the Chamber of Deputies to instrument for $g^{p c}$ (as discussed before) and (ii) the provincial population dependency ratio (defined as the population share under 15 years old and older than 65 years old over the population between 15 and 65 years old) to instrument for $\theta$ (and, of course, $1-\theta$ as well).

\footnotetext{
${ }^{31}$ As discussed in Vegh and Vuletin (2015), dividing the absolute distortion in the Chamber of Deputies in each constitutional reform by the respective population in the year of each constitutional reform controls for the fact that, for a given level of absolute distortion, provinces with smaller population benefit on a per capita basis by a larger margin than more populous provinces.

${ }^{32}$ Since constitutional amendments affected the degree of over-representation in the Chamber of Deputies three times (i.e., 1949, 1972, and 1983), the effective distortion measure in the Chamber of Deputies only changes two times in the period under analysis.

${ }^{33}$ Indeed, when estimating the two-stage least- squares regression, and based on Stock and Yogo (2005), we reject the null hypothesis that the effective distortion in the Chamber of Deputies is a weak instrument for provincial primary spending per capita.
} 
More precisely, we instrument $g c^{p c}$ and $g i^{p c}$ using (i) the provincial effective distortion in the Chamber of Deputies, (ii) the provincial population dependency ratio, and (iii) the interaction term between provincial effective distortion in the Chamber of Deputies and the provincial population dependency ratio. What is the rationale for using the provincial population dependency ratio to instrument the composition of provincial primary spending, in particular, between government consumption and public investment? Several studies have found that larger levels of population dependency increase both current primary spending, especially health spending and social security for the population over 65 years old, and education and health for the young population (e.g., Hagemann and Nicoletti, 1989; Poterba 1997 and 1998, Visco, 2001; Sanz and Velazquez, 2007; Cattaneo and Wolter, 2009; Sorensen, 2013). Therefore, higher population dependency ratios should, in principle, be associated with larger current primary spending and lower public investment shares out of primary spending. Panels A and B in Figure 12 show that this is, indeed, the case for Argentine provinces, even after controlling for provincial fixed effects and linear and quadratic trends (at a 1 percent level of significance). Moreover, Panels D and E show that this strong regularity also holds for a global sample of countries, also after controlling for country fixed effects and linear and quadratic trends (at a 1 percent level of significance). ${ }^{34}$ For exogeneity considerations, it proves important to note that the population dependency ratio is calculated based on age demographic variables and not on labor related variables (such as labor force or its participation rate) which, in turn, reduces the response of the population dependency ratio to short-run macroeconomic fluctuations. Moreover, Panels C and D in Figure 12 confirm that there is no statistical relationship between the population dependency ratio and real GDP growth in Argentine provinces or at a global level, respectively. In other words, the population dependency ratio proves to be a plausible exogenous instrument to explain the composition of primary spending, in particular, between government consumption and public investment. ${ }^{35}$

\section{FIGURE 12}

To allow the size of the public investment multiplier to depend upon the ratio of the initial stock of public capital to GDP, we modify our linear specification (7) as follows:

$$
y_{i, t}^{p c}=\alpha_{i}+\beta^{c} g c_{i, t}^{p c}+\beta^{i} g i_{i, t}^{p c}+\left(\beta^{i} g i_{i, t}^{p c} \cdot s t o c k_{i, 0}\right)+\lambda y_{i, t-1}^{p c}+\varrho T+v T^{2}+\mu_{i, t},
$$

\footnotetext{
${ }^{34}$ Because of the inclusion of country fixed effects and linear and quadratic trends, we only consider countries with at least 40 years of data. Due to this restriction, 43 countries are included in Panels D and E.

${ }^{35}$ Indeed, when estimating the two-stage least squares regression, and based on the Kleibergen-Paap rk Wald f statistic, we reject the null hypothesis that the proposed instruments are a weak instrument for provincial government consumption per capita and provincial public investment per capita.
} 
where the only difference is the interaction term between the public investment shock and stock $_{i, 0}$ (the initial stock of public capital over GDP in each province). Since there is no data for the stock of public capital in each Argentine province, we construct a proxy based on newly collected data, from different historical archives, on the kilometers of paved highways in each province. ${ }^{36}$ In particular, we use the ratio of actual kilometers of paved highways to predicted kilometers of paved highways based on provincial GDP (for a balanced panel for the entire period under analysis). When this ratio is larger (smaller) than one, it indicates that the province-year observation under consideration has an endowment of paved highways that is larger (smaller) than that predicted based on its GDP. To avoid possible endogeneity problems, we use this proxy for the stock of public capital over GDP observed in each province in $1964 .{ }^{37}$ Since by construction $s t o c k_{i, 0}$ is constant for each province, stock $k_{i, 0}$ is not included in specification (2) for control purposes because it is absorbed by the provincial fixed effect. Unfortunately, there are no long-enough time series for private consumption and private investment at the provincial level to explore the mechanisms involved.

\subsection{Empirical results}

Figure 13 shows that the provincial primary spending multiplier is lower than one; that is, $0.56(t=2.5)$. This small provincial primary spending multiplier is in line with existing evidence for Argentina on the effects of central government fiscal shocks on GDP based on SVAR techniques (see Avramovich, Basso, and Resk, 2006; Anos-Casero, Cerdeiro, and Trezzi, 2010; and Puig, 2014). As in the case of the European sample of Section 2.2 and U.S. states of Section 3.2, it is worth noting that the findings for government consumption multipliers (not shown for the sake of brevity) are similar to those of primary spending multipliers. ${ }^{38}$

We now turn to public investment multipliers. The public investment multiplier is rather large, $1.60(t=2.0)$. In fact, we cannot reject the null hypothesis that the multiplier is equal to one. This result is in line with the effects of central government fiscal shocks on Argentina's GDP based on SVAR techniques (Puig, 2014). Interestingly enough, if one used our proxy for the average stock of public capital over GDP for Argentina for the period covered in this analysis (i.e., 1964-2014), but relied on the findings of Section 2.3 (i.e., conducted an out-of-sample exercise based on the findings of such section), the estimated public investment multiplier would be of $1.71(t=2.4)$, which is quite similar to the one found using provincial

\footnotetext{
${ }^{36}$ See Appendix 1 for a detailed description of data definitions and sources.

${ }^{37}$ If this proxy for the initial stock of public capital over GDP is allowed to change over time for estimation purposes (e.g., by using the value of such a measure in $t-1$ ), similar results are obtained. Results are not shown for the sake of brevity.

${ }^{38}$ This is not surprising considering that current primary spending typically represents about 90 percent of primary spending for Argentine provinces.
} 
data and an instrumental variables approach. ${ }^{39}$

\section{FIGURE 13}

We now test whether our proxy for the initial stock of public capital over GDP actually matters for the determination of the size of the public investment multiplier. Interestingly, and highly important for identification purposes, Figure 14 shows the large variability of our proxy for the initial stock of public capital over GDP across Argentine provinces, with a coefficient of variation of 0.69 . While the average ratio is about 0.50 , the ratio is below 0.20 for some provinces (including Tierra del Fuego, Formosa, and Misiones) and reaches values of 1.15 for some other provinces (including Mendoza, Santa Fe, Cordoba, and Buenos Aires).

\section{FIGURE 14}

Using specification (8), Figure 13 shows that the public investment multiplier associated with our proxy for a high initial stock of public capital over GDP, $0.23(t=0.85)$, is much smaller than that associated with our proxy for a low initial stock of public capital over GDP, $2.03(t=2.3) .{ }^{40}$ In fact, we cannot reject the null hypothesis that the former multiplier is statistically zero and we cannot reject the null that the latter multiplier is larger than one.

Like Figure 4 for the European sample and Figure 9 for U.S. states, Figure 15 shows the crucial effect of our proxy for the initial stock of public capital over GDP on the size of the provincial public investment multiplier. While the multiplier is virtually zero for high levels of this ratio (i.e., higher than 1.20), it becomes statistically significant and increasingly positive with lower initial ratios. Moreover, for sufficiently low levels of this ratio (i.e., lower than 0.30), the public investment multiplier becomes larger than one. In other words, the increase (fall) of GDP associated with increasing (reducing) provincial public investment by $\$ 1$ tends to be zero for high levels of the initial stock of public capital over GDP in each province and becomes larger as the initial ratio decreases.

\section{FIGURE 15}

These findings have important policy implications given that our proxy for the initial stock

\footnotetext{
${ }^{39}$ Moreover, as in the case of the public investment multiplier estimated in this section for the Argentine provinces $(1.6, t=2.0)$, we cannot reject the null hypothesis that the out-of-sample public investment multiplier $(1.71, t=2.4)$ equals one statistically speaking.

${ }^{40}$ As in Sections 2.3 and 3.2 for the European and United States states samples, respectively, we use the 5th and 95th percentiles to identify low and high initial stocks of public capital over GDP ratios, respectively, in Argentine provinces.
} 
of public capital over GDP ratio varies greatly across Argentine provinces (and over time) and thus so will the size of the public investment multipliers. Figure 16 shows the implied public investment multipliers for Argentine provinces given our proxy for the stock of public capital over GDP ratio in, for example, the years 1964 (Panel A), 1990 (Panel B), and 2014 (Panel C). Interestingly, the province of Buenos Aires (which accounts for about 40 percent of Argentina's GDP) and which has increased its GDP almost 3-fold since 1964 has barely increased its stock of paved highways (with less than a 10 percent increase from 4,300 km in 1964 to about $4,700 \mathrm{~km}$ in 2014). For this reason, its public investment multiplier almost doubled from 0.80 in 1964 to 1.50 in 2014. In contrast, other provinces, including the province of La Rioja, have increased their stock of paved highways by about 5-fold from $392 \mathrm{~km}$ in 1964 to about $1,900 \mathrm{~km}$ in 2014. As a result, its public investment multiplier fell from 1.62 in 1964 to virtually zero in 2014 .

\section{FIGURE 16}

In sum, this empirical evidence for Argentine provinces using an instrumental variables approach also supports the importance of the initial stock of public capital over GDP in determining the size of the public investment multiplier. Moreover, the specific size of the public investment multiplier (as well as its evolution over time) obtained in this section matches quite well that of Section 2.3 (when conducting an out-of-sample exercise for Argentina). These results thus provide further support for our empirical findings.

\section{$5 \quad$ External studies as additional evidence}

Sections 2, 3, and 4 provided strong empirical evidence based on European countries, U.S. states, and Argentine provinces and relying on alternative identification strategies including Blanchard-Perotti time identification, forecast errors, and instrumental variables approaches, respectively, in favor of the importance of the initial stock of public capital over GDP in determining the size of the public investment multiplier.

We now resort to external evidence. In particular, we compile values for public investment multipliers from 17 country studies (mostly studies conducted by researchers working in finance ministries, central banks, international financial institutions, and other non-government entities). We compare these findings to those obtained with our non-linear estimates of Section 2 (i.e., based on a sample of 31 European countries).

Panel A in Figure 17 shows, for each of the 17 countries, the estimate reported in solid grey bars vis-à-vis the respective figure based on our non-linear estimates of Section 2 in 
dotted-filled bars, given the relevant ratio of the initial stock of public capital to GDP. ${ }^{41}$ Countries are ordered in increasing order based on the size of the public investment multiplier from the external source. While the match is, naturally, not perfect, it is truly remarkable. In fact, Panel B in Figure 17 shows the same evidence presented as a regression. Two points are worth making. First, the $R^{2}$ is very high (i.e., 0.82), which is consistent with the visual impression of Panel A. Second, we cannot reject the null that the coefficient relating both metrics equals one.

\section{FIGURE 17}

\section{Final thoughts}

This paper has empirically analyzed an overlooked dimension of public investment multipliers: how does the initial stock of public capital (measured as the ratio of the initial stock of capital to GDP) affect their size? Basic neoclassical theory would tell us that the higher (lower) this initial ratio, and hence the lower (higher) the marginal productivity of public capital, the lower (higher) should be the public investment multiplier. This is a critical dimension, particularly for developing countries, where there are large gaps in public investment/infrastructure. An empirical confirmation of this theoretical presumption should provide further impetus to major existing plans to improve and build infrastructure in developing countries.

Our answer to the above question is clear and unequivocal: public investment multipliers do indeed depend on the initial stock of public capital. We provide strong evidence based on different samples (European countries, U.S. states, and Argentina provinces) and using very different strategies to identify exogenous public investment shocks (Blanchard-Perotti, forecast errors, and instrumental variables). In all cases, we consistently find that public investment multipliers in low initial public capital countries are significantly higher than in high initial public capital countries. Further, out-of-sample estimations based on one of our empirical models match remarkably well the public investment multiplier estimates provided in 17 independent country studies.

\footnotetext{
${ }^{41}$ See Appendix 2 for details.
} 


\section{References}

Alesina, A., C. Favero, and F. Giavazzi, "The Output Effect of Fiscal Consolidation Plans," Journal of International Economics 96 (2015), S19-S42.

Alfaro, L., S. Kalemli-Ozcan, and V. Volosovych, "Why Doesn't Capital Flow from Rich to Poor Countries? An Empirical Investigation," Review of Economics and Statistics 90 (2008), 347-368.

Anos-Casero, P., D. Cerdeiro, and R. Trezzi, "Estimating the Fiscal Multiplier in Argentina," World Bank Policy Research Working Paper Series 5220 (2010).

Aschauer, D., "Is Public Expenditure Productive?" Journal of Monetary Economics 23 (1989a), 177-200.

Aschauer, D., "Does Public Capital Crowd Out Private Capital?" Journal of Monetary Economics 24 (1989b), 171-188.

Atlas, C., T. Gilligan, R. Hendershott, and M. Zupan, "Slicing the Federal Government Net Spending Pie: Who Wins, Who Loses and Why," American Economic Review 85 (1995), 624-629.

Atlas, C., and R. Hendershott, "Optimal Effort Allocation by U.S. Senators: The Role of Constituency Size," Public Choice 92 (1997), 221-229.

Auerbach, A., and Y. Gorodnichenko, "Measuring the Output Responses to Fiscal Policy," American Economic Journal 4 (2012), 1-27.

Auerbach, A., and Y. Gorodnichenko, "Fiscal Multipliers in Recession and Expansion," in A. Alesina and F. Giavazzi, eds., Fiscal Policy After the Financial Crisis (Illinois: University of Chicago Press, 2013), 63-98.

Avramovich, B., M. Basso, and E. Rezk, "Dynamic Effects of Fiscal Shocks Upon Diverse Macroeconomic Variables: A Structural VAR Analysis for Argentina," CEPAL XVIII Seminario Regional de Política Fiscal (2006).

Baxter, M., and R. King, "Fiscal Policy in General Equilibrium," American Economic Review 83 (1993), 315-334.

Berg, A., E. Buffie, C. Pattillo, R. Portillo, A. Presbitero, and L.F. Zanna, "Some Misconceptions About Public Investment Efficiency and Growth," Economica 86 (2019), 409-430.

Blanchard, O., and R. Perotti, "An Empirical Characterization of the Dynamic Effects of Changes in Government Spending and Taxes on Output," Quarterly Journal of Economics 117 (2002), 1329-1368.

Calderon, C., E. Moral-Benito, and L. Serven, "Is Infrastructure Capital Productive? A Dynamic Heterogeneous Approach," Journal of Applied Econometrics 30 (2015), 177-198. 
Cattaneo, M., and S. Wolter, "Are the Elderly a Threat to Educational Expenditures?" European Journal of Political Economy 25 (2009), 225-236.

Cavallo, E., and C. Daude, "Public Investment in Developing Countries: A Blessing or a Curse?" Journal of Comparative Economics 39 (2011), 65-81.

Chinn, M.D. and H. Ito, "What Matters for Financial Development? Capital controls, Institutions, and Interactions," Journal of Development Economics 81 (2006), 163-192.

Christiano, L., M. Eichenbaum, and S. Rebelo, "When is the Government Spending Multiplier Large?" Journal of Political Economy 119 (2011), 78-121.

Clemens, J., and S. Miran, "Fiscal Policy Multipliers on Subnational Government Spending," American Economic Journal 4 (2012), 46-68.

Coenen, G., R. Straub, and M. Trabandt, " Journal of Economic Dynamics and Control 37 (2013), 367-386.

Coenen, G., C. Erceg, C. Freedman, D. Furceri, M. Kumhof, R. Lalonde, D. Laxton, J. Lindé, A. Mourougane, D. Muir, S. Mursula, C. De Resende, J. Roberts, W. Roeger, S. Snudde, M. Trabandt, and J. Veld, "Effects of Fiscal Stimulus in Structural Models," American Economic Journal: Macroeconomics 4 (2012), 22-68.

Driscoll, J., and A. Kraay, "Consistent Covariance Matrix Estimation with Spatially Dependent Panel Data," Review of Economics and Statistics 80 (1998), 549-560.

Eden, M., and A. Kraay, "Crowding In and the Returns to Government Investment in Low-Income Countries," The World Bank Policy Research Working Paper Series 678 (2014).

Frankel, J., C. Vegh, and G. Vuletin, "On Graduation from Fiscal Procyclicality," Journal of Development Economics 100, 32-47.

Furceri, D., and B. Li, "The Macroeconomic (and Distributional) Effects of Public Investment in Developing Economies," IMF Working Paper 17/217 (2017).

Gonzalez-Garcia, J., A. Lemus, and M. Mrkaic, "Fiscal Multipliers in the ECCU," IMF Working Paper 13/117 (2013).

Hagemann, R., and G. Nicoletti, "Ageing Populations: Economic Effects and Implications for Public Finance," OECD Economics Department Working Papers 61 (1989).

Holcombe, R., and A. Zardkoohi, "The Determinants of Federal Grants," Southern Economic Journal 48 (1981), 393-399.

Ilzetzki, E., E. Mendoza, and C. Vegh, "How Big (Small?) Are Fiscal Multipliers?" Journal of Monetary Economics 60 (2013), 239-254.

Ilzetzki, E., C.M. Reinhart, and K. Rogoff, "Exchange Arrangements Entering the 21st Century: Which Anchor Will Hold?" NBER Working Paper No. 23134 (2017).

Im, K., M. Pesaran, and Y. Shin, "Testing for Unit Roots in Heterogeneous Panels," 
Journal of Econometrics 115 (2003), 53-74.

Izquierdo, A., C. Pessino, and G. Vuletin, Smart Spending for Better Lives, IDB Flagship Development in the Americas (2018).

Jorda, O., "Estimation and Inference of Impulse Responses by Local Projections," American Economic Review 95 (2005), 161-182.

Knight, B., "Legislative Representation, Bargaining Power and the Distribution of Federal Funds: Evidence from the U.S. Congress," Economic Journal 118 (2008), 1785-1803.

Huidrom, R., A. Kose, J. Lim, and F. Ohnsorge, "Why Do Fiscal Multipliers Depend on Fiscal Positions?" Journal of Monetary Economics (2019), forthcoming.

Kose, A., S. Kurlat, F. Ohnsorge, and N. Sugawara, "A Cross-Country Database of Fiscal Space," The World Bank Policy Research Working Paper 8157 (2017).

Leeper, E., T. Walker, and S. Yang, "Government Investment and Fiscal Stimulus," Journal of Monetary Economics 57 (2010), 1000-1012.

Leduc, S., and D. Wilson, "Roads to Prosperity or Bridges to Nowhere? Theory and Evidence on the Impact of Public Infrastructure Investment," NBER Working Papers 18042 (2012).

Lucas, R., "Why Doesn't Capital Flow from Rich to Poor Countries?" American Economic Review 80 (1990), 92-96.

Owyang, M., V. Ramey, and S. Zubairy, "Are Government Spending Multipliers Greater during Periods of Slack? Evidence from 20th Century Historical Data," NBER Working Papers 18769 (2013).

Porto, A., Disparidades Regionales y Federalismo Fiscal (La Plata: EDULP, 2004).

Porto, A., and P. Sanguinetti, "Political Determinants of Intergovernmental Grants: Evidence from Argentina," Economics and Politics 13 (2001), 237-256.

Poterba, J., "State Responses to Fiscal Crises: The Effects of Budgetary Institutions and Politics," Journal of Political Economy 102 (1994), 799-821.

Poterba, J., "Demographic Structure and the Political Economy of Public Education," Journal of Policy Analysis and Management 16 (1997), 48-66.

Poterba, J., "Demographic Change, Intergenerational Linkages, and Public Education," American Economic Review 88 (1998), 315-320.

Puig, J., "Multiplicador del Gasto Público en Argentina," Económica 60 (2014), 188-210.

Ramey, V., "Macroeconomic Shocks and Their Propagation," Handbook of Macroeconomics, Volume 2A (2016), 71-162.

Riera-Crichton, D., C. Vegh, and G. Vuletin, "Procyclical and Countercyclical Fiscal Multipliers: Evidence from OECD Countries," Journal of International Money and Finance 
52 (2015), 15-31.

Sanz, I., and F. Velazquez, "The Role of Ageing in the Growth of Government and Social Welfare Spending in the OECD," European Journal of Political Economy 23 (2007), 917-931.

Sorensen, R., "Does Aging Affect Preferences for Welfare Spending? A Study of Peoples' Spending Preferences in 22 Countries, 1985-2006," European Journal of Political Economy 29 (2013), 259-271.

Sorensen, B., L. Wu, and O. Yosha, "Output Fluctuations and Fiscal Policy: U.S. State and Local Governments 1978-1994," European Economic Review 45 (2001), 1271-1310.

Stock, J., and M. Watson, "Why Has U.S. Inflation Become Harder to Forecast?" Journal of Money, Banking and Credit 39 (2007), 1-33.

Stock, J., and M. Yogo, "Testing for Weak Instruments in Linear IV Regression" in J. Stock and D.W.K. Andrews, eds., Identification and Inference for Econometric Models: Essays in Honor of Thomas J. Rothenberg (Massachusetts: Cambridge University Press, 2005), 80-109

Tornell, A., and A. Velasco, "The Tragedy of the Commons and Economic Growth: Why Does Capital Flow from Poor to Rich Countries?" Journal of Political Economy 100 (1992), 1208-1231.

Vegh, C., and G. Vuletin, "Unsticking the Flypaper Effect in an Uncertain World," Journal of Public Economics 131 (2015), 142-155.

Visco, I., "Paying for Pensions: How Important is Economic Growth?" PSL Quarterly Review 54 (2001), 73-102.

Zegeye, A., "U.S. Public Infrastructure and Its Contribution to Private Sector Productivity," BLS Working Paper 329 (2000). 


\section{Appendix 1. Data definitions and sources}

\section{European sample}

Government spending and macroeconomic variables cover 31 European countries with quarterly data starting in the following year-quarter for each country: Austria (1999:Q1), Belgium (1995:Q1), Bulgaria (1999:Q1), Croatia (2012:Q1), Cyprus (1995:Q1), Czech Republic (1999:Q1), Denmark (1999:Q1), Estonia (1999:Q1), Finland (1998:Q1), France (1991:Q1), Germany (1995:Q1), Greece (1999:Q1), Hungary (1999:Q1), Iceland (2004:Q1), Ireland (1999:Q1), Italy (1999:Q1), Latvia (1999:Q1), Lithuania (1999:Q1), Luxembourg (2000:Q1), M5alta (2000:Q1), Netherlands (1999:Q1), Norway (1996:Q1), Poland (2002:Q1), Portugal (1999:Q1), Romania (199:Q1), Slovakia (1999:Q1), Slovenia (1999:Q1), Spain (1995:Q1), Sweden Kingdom (1993:Q1), Switzerland (1990:Q1), and United Kingdom (1987:Q1).

The source for government finance and national accounts statistics is Eurostat.

The ratio of public stock of capital to GDP is from IMF-FAD (general government capital stock) at annual frequency. The ratio of the initial stock of public capital to GDP is computed in all countries as the average for the years 1980-1985, with the exception of Croatia, Czech Republic, Estonia, Latvia, Lithuania, Slovakia, and Slovenia for which the average is computed over the period 1990-1995.

The variable efficiency is obtained as the first principal component of a wide set of indicators (36 to be specific) of institutional quality as well as indicators for the quality of infrastructure, education, and health. These indicators are taken from the Global Competitiveness report, which is published by the World Economic Forum and covers 142 countries for the period 2004-2014.

The following indicators are used for overall institutional quality: property rights, intellectual property protection, diversion of public funds, public trust in politicians, irregular payments and bribes, judicial independence, favoritism in decisions of government officials, wastefulness of government spending, burden of government regulation, efficiency of legal framework in settling disputes, efficiency of legal framework in challenging regulations, transparency of government policymaking, business costs of terrorism, business costs of crime and violence, organized crime, reliability of police services, ethical behavior of firms, strength of auditing and reporting standards, efficacy of corporate boards, protection of minority shareholders' interests, strength of investor protection, and government procurement of advanced tech products.

The following indicators are used for infrastructure quality: quality of overall infrastructure, quality of roads, quality of railroad infrastructure, quality of port infrastructure, quality 
of air transport infrastructure, and quality of electricity supply.

The following indicators are used for education and health quality: quality of primary education, quality of the education system, quality of math and science education, quality of management schools, quality of scientific research institutions, business impact of malaria, business impact of tuberculosis, and business impact of HIV/AIDS.

\section{U.S. states}

Total State Expenditures (estimated and actual) - Capital Inclusive. National Association of Budget Officers, State Expenditure Report.

Total capital expenditures (estimated and actual) - Capital inclusive. National Association of Budget Officers, State Expenditure Report.

Real gross domestic product. Bureau of Economic Activity. Regional Accounts.

Total, private and public stock of capital. Zegeye (2000). The shares of the stock of public capita over GDP per state for 2012 are obtained using the shares of consumption expenditure from the U.S. Bureau of Economic Analysis and the U.S. fiscal data provided by the U.S. Census Bureau in the 2012 Census of Government. These shares are then applied to the total stock of public capital in the U.S. obtained from the Investment and Capital Stock Dataset from the Fiscal Affairs Department at the IMF. The same is true for the estimate for the period 1980-1985.

\section{Argentine provinces}

The total subnational public expenditure, as well as its components (consumption and investment), and total transfers from federal government to the provinces come from Porto (2004) for the period 1964-2000. For the period 2001-2014, information from the Ministry of Economy and Public Finance of the Republic was used.

The subnational Geographical Gross Product comes from Porto (2004) for the period 19642000. For the period 2001-2014, data are from the Center for Production Studies (CEP), which reports to the Argentina Ministry of Industry. The years not registered by the CEP for this period were completed with data from the Provincial Statistics Offices of each province and information from the Secretariat of Economic Policy and Development Planning, which depends on the Ministry of Economy and Public Finance of the Argentine Republic.

The provincial population comes from Porto (2004) for the period 1964-2000 and from the National Institute of Statistics and Census (INDEC) for the period 2001-2014.

Effective distortion in Chamber of Deputies is from Vegh and Vuletin (2015). 
Kilometers of paved highways in each province. From 1964 to 2001, the data are from historical archives from (i) Anuarios Estadísticos del Instituto Nacional de Estadística y Censos (INDEC), (ii) Censos Nacionales Económicos del INDEC, and (iii) Dirección de Vialidad Nacional y de Oficinas de Estadisticas Provinciales. From 2001 to 2014, the data are from Observatorio Nacional de Datos de Transporte - Centro Tecnológico de Transporte, Tránsito y Seguridad Vial de la Universidad Tecnológica Nacional.

\section{Appendix 2. External studies and own calibrations}

Table 1 compares the public investment multiplier for each of the 17 country-specific external studies with the one estimated based on our non-linear arguments of Section 2. All references for this appendix are listed in the note to Table 1. As in Section 2, we use IMF-FAD (general government capital stock) at annual frequency to compute the public stock of capital over GDP ratio for these 17 countries. 
Table 1. Public investment multiplier for each of the 17 country-specific external studies and the one estimated based on our non-linear arguments of Section 2.

\begin{tabular}{|c|c|c|c|c|c|}
\hline \multirow[b]{2}{*}{ Country } & \multicolumn{3}{|c|}{ From country-specific external study } & \multicolumn{2}{|c|}{ Based on empirical results from Section 2} \\
\hline & Study & $\begin{array}{l}\text { Methodology and sample } \\
\text { used }\end{array}$ & $\begin{array}{l}\text { Public investment } \\
\text { multiplier }\end{array}$ & $\begin{array}{l}\text { Average ratio of stock of } \\
\text { public capital to GDP over } \\
\text { relevant/available period }\end{array}$ & $\begin{array}{l}\text { Implied public } \\
\text { investment multiplier } \\
\text { (after two years) }\end{array}$ \\
\hline Algeria & $\begin{array}{l}\text { Elkhdari, Souissi, and } \\
\text { Jewel (2018) }\end{array}$ & $\begin{array}{l}\text { SVAR, 2000-2015, } \\
\text { impact on non-oil GDP }\end{array}$ & 0.4 (after two years) & $1(2000-2015)$ & 0.42 \\
\hline Argentina & Puig (2014) & SVAR, 1993-2012 & 1.03 (after two years) & $0.4(1993-2012)$ & 1.29 \\
\hline Australia & $\begin{array}{l}\text { Hunt, Tumbarello, } \\
\text { and Takáts (2009) }\end{array}$ & DSGE model & 1.22 & $0.35(1980-2008)$ & 1.42 \\
\hline Cameroon & Chuling et al. (2018) & SVAR, 1999-2015 & 0.82 (after two years) & $0.40(1999-2015)$ & 1.29 \\
\hline Colombia & Rincón et al. (2017) & DSGE model, 2000-2014 & 0.45 & $0.80(2000-2014)$ & 0.63 \\
\hline Czech Republic & Ambriško et al. & DSGE model & 0.99 (after two years) & $0.50(1993-2013)$ & 1.08 \\
\hline Germany & Veld (2016) & $\begin{array}{l}\text { European Commission's } \\
\text { macro QUEST model }\end{array}$ & 0.57 (after two years) & $0.70(1960-2015)$ & 0.76 \\
\hline Italy & $\begin{array}{l}\text { Renzi and Padoan } \\
\text { (2016) }\end{array}$ & $\begin{array}{l}\text { Italian Treasury } \\
\text { Econometric Model, } \\
\text { 2007-2014 }\end{array}$ & 0.9 (after two years) & $0.65(2007-2014)$ & 0.83 \\
\hline Japan & $\begin{array}{l}\text { Brückner and } \\
\text { Tuladhar }(2010)\end{array}$ & $\begin{array}{l}\text { Panel VAR at prefecture } \\
\text { level, } 1990-2010\end{array}$ & 0.26 & $1.25(1990-2010)$ & 0.21 \\
\hline Korea & $\begin{array}{l}\text { Eskesen and Lueth } \\
\text { (2009) }\end{array}$ & DSGE model & 0.8 & $0.60(2000-2008)$ & 0.91 \\
\hline Netherdlands & Veld (2016) & $\begin{array}{l}\text { European Commission's } \\
\text { macro QUEST model }\end{array}$ & 0.53 (after two years) & $0.85(1960-2015)$ & 0.58 \\
\hline Paraguay & David (2017) & VAR, 2003-2016 & 0.9 (after two years) & $0.50(2003-2016)$ & 1.08 \\
\hline Peru & $\begin{array}{l}\text { Central Reserve Bank } \\
\text { of Peru (2012) }\end{array}$ & VAR, 1992-2012 & 1.42 (in the medium-term) & $0.35(1992-2012)$ & 1.42 \\
\hline Saudi Arabia & $\begin{array}{l}\text { Espinoza and } \\
\text { Senhadji (2011) }\end{array}$ & $\begin{array}{l}\text { VAR, } 1975-2009 \text {, } \\
\text { impact on non-oil GDP }\end{array}$ & 0.6 (after two years) & $0.9(1975-2009)$ & 0.52 \\
\hline Spain & $\begin{array}{l}\text { Pareira and Flores de } \\
\text { Frutos (1999) }\end{array}$ & VAR, 1970-1989 & 0.65 (after two years) & $0.55(1970-1989)$ & 0.99 \\
\hline Tunisia & $\begin{array}{l}\text { Diop and Ben } \\
\text { Abdallah (2009) }\end{array}$ & SVECM, 1997-2008 & 0.30 (after two years) & $1(1970-1989)$ & 0.42 \\
\hline United States & Coenen et al. (2012) & Different DSGE models & 1 & $0.65(2000-2015)$ & 0.83 \\
\hline
\end{tabular}

References: Elkhdari, M., M. Souissi, and M. Jewell, "Empirical Estimation of Fiscal Multipliers in MENA Oil-Exporting Countries with an Application to Algeria," IMF Working Paper 18/124 (2018). Puig, J., "Multiplicador del Gasto Público en Argentina," Económica 60 (2014), 188-210. Hunt, B., P. Tumbarello, and E. Takáts, "Australia: Selected Issues," IMF Country Report 09/249 (2009). Chuling, B., K. Kalonji, M. Sow, M. Macdonald, D. Tchakoté, and J. Jellema, "Cameroon: Selected Issues," IMF Country Report 18/256 (2018). Rincón, H., D. Rodríguez, J. Toro, and S. Téllez, "FISCO: Modelo Fiscal para Colombia," Ensayos sobre Política Económica 35 (2017), 161-187. Ambriško, R., J. Babecký, J. Ryšánek, and V. Valenta, "Assessing the Impact of Fiscal Measures on the Czech Economy," Economic Modelling 44 (2015), 350-357. Veld, J., "Public Investment Stimulus in Surplus Countries and their Euro Area Spillovers," European Commission Economic Brief 16 (2016), 16. Renzi, M. and P. Padoan, "Economic and Financial Document - April," Ministerio dell'Economia e delle Finnanze (2016). Brückner, M., and A. Tuladhar, "Public Investment as a Fiscal Stimulus: Evidence from Japan's Regional Spending During the 1990s," IMF Working Paper 10/110 (2010). Eskesen, L. and E. Lueth, "Republic of Korea: Selected Issues," IMF Country Report 09/263 (2009). David, M., "Fiscal Policy Effectiveness in a Small Open Economy: Estimates of Tax and Spending Multipliers in Paraguay," IMF Working Paper 17/63 (2017). Central Reserve Bank of Peru, "Inflation Report - June: Recent Trends and Macroeconomic Forecasts 2012-2014," (2012). Espinoza, R.A. and A. Senhadji, "How Strong Are Fiscal Multipliers in the GCC? An Empirical Investigation," IMF Working Paper 11/61 (2011). Pereira, A. and R. Flores de Frutos, "Public Capital Accumulation and Private Sector Performance," Journal of Urban Economics 46 (1999), 300-322. Diop, N. and N. Ben Abdallah, "The Dynamic Effects of Countercyclical Fiscal Stimulus on Output in Tunisia," World Bank Policy Research Working Paper 5087 (2009). Coenen, G., C. Erceg, C. Freedman, D. Furceri, M. Kumhof, R. Lalonde, D. Laxton, J. Lindé, A. Mourougane, D. Muir, S. Mursula, C. De Resende, J. Roberts, W. Roeger, S. Snudde, M. Trabandt, and J. Veld, "Effects of Fiscal Stimulus in Structural Models," American Economic Journal: Macroeconomics 4 (2012), 22-68. 
Figure 1. Primary spending and public investment multipliers: Evidence from European countries

Panel A. Effect of primary spending on GDP

1.5

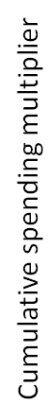

0.5

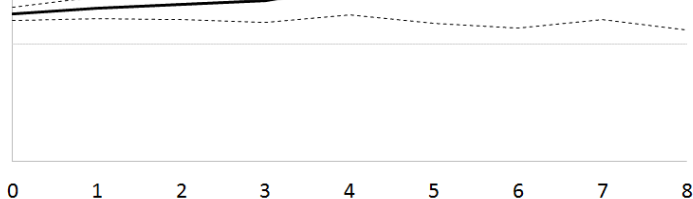

Quarter

Panel B. Effect of primary spending on private consumption

1.5

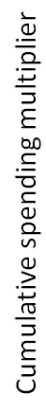

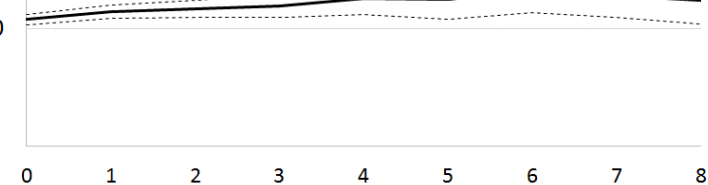

Quarter

Panel C. Effect of primary spending on private investment

1.5

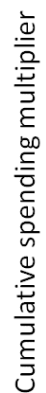

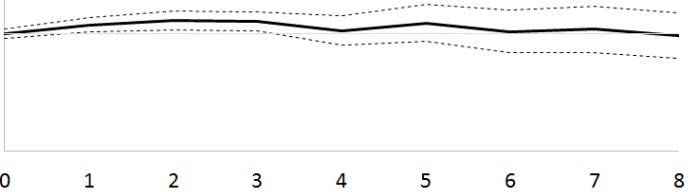

Panel D. Effect of public investment on GDP

1.5

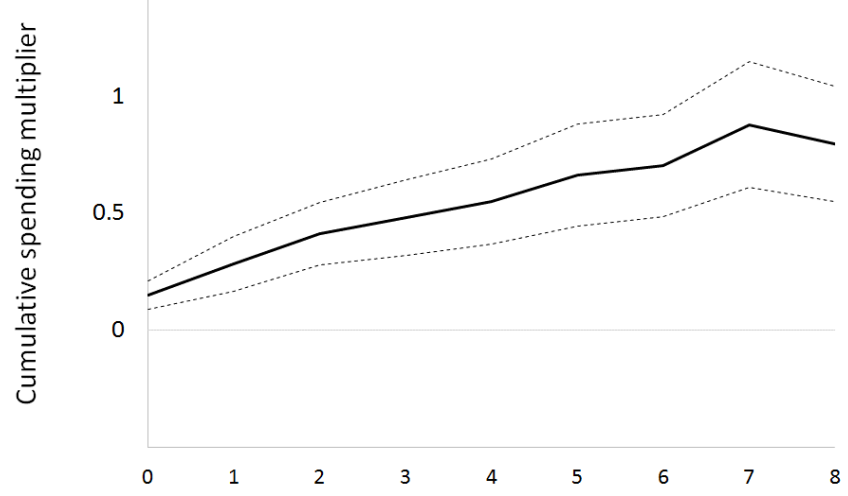

Quarter

Panel E. Effect of public investment on private consumption

1.5

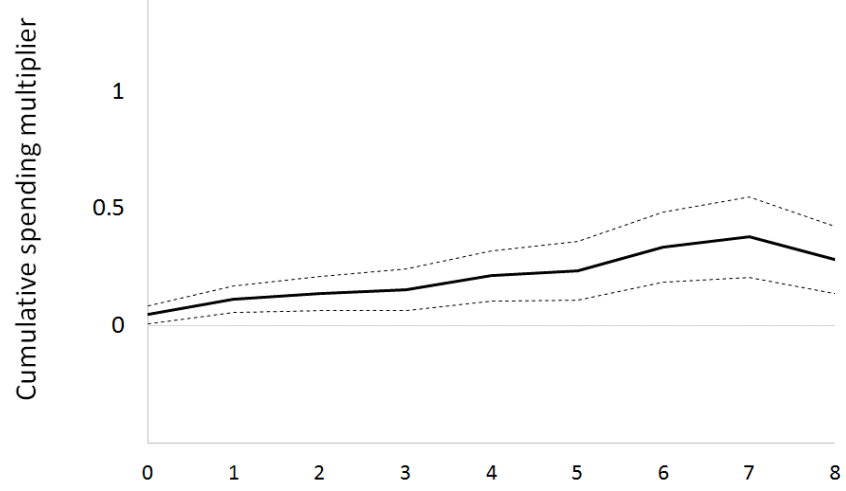

Quarter

Panel F. Effect of public investment on private investment

1.5

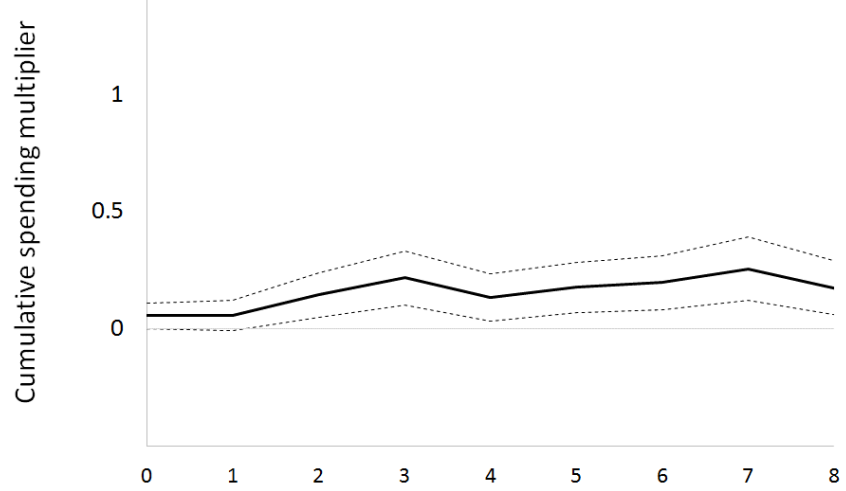

Quarter

Quarter

Notes: Country fixed effect panel regression with linear and quadratic trends, standard errors are Driscoll-Kraay standard errors and bootstrapped. 
Figure 2. Ratio of initial stock of public capital to GDP in European countries

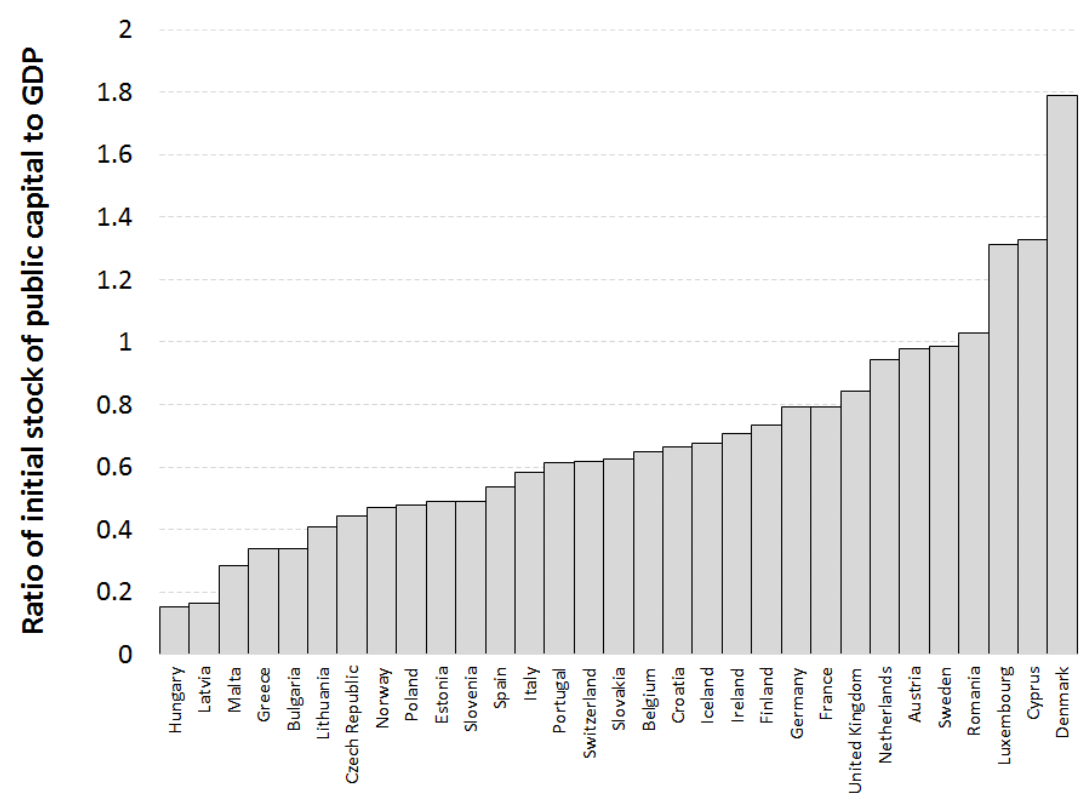


Figure 3. Public investment multiplier: Evidence from European countries

(Evaluated at high, 95th percentile, and low, 5th percentile, initial stock of public capital over GDP ratios)

Panel A. Effect on GDP, evaluated at high ratio of initial stock of public capital to GDP

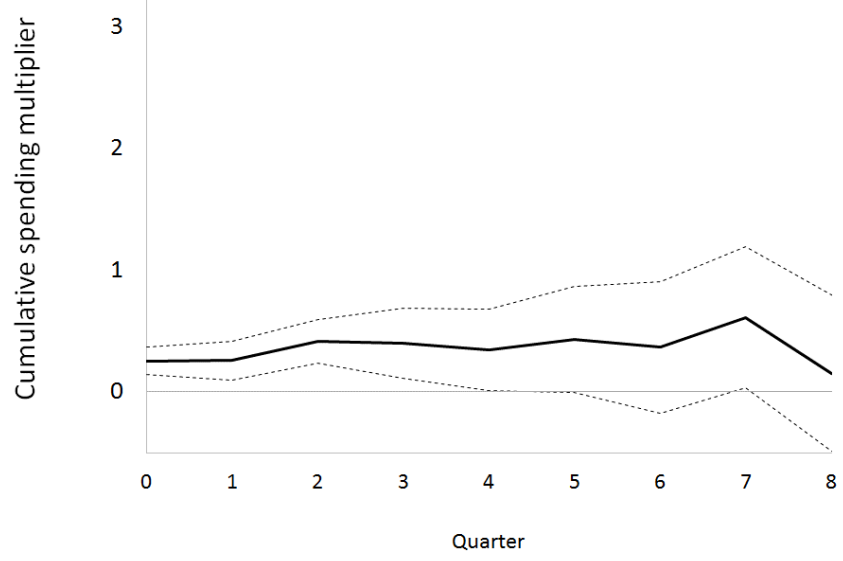

Panel B. Effect on private consumption, evaluated at high ratio of initial stock of public capital to GDP

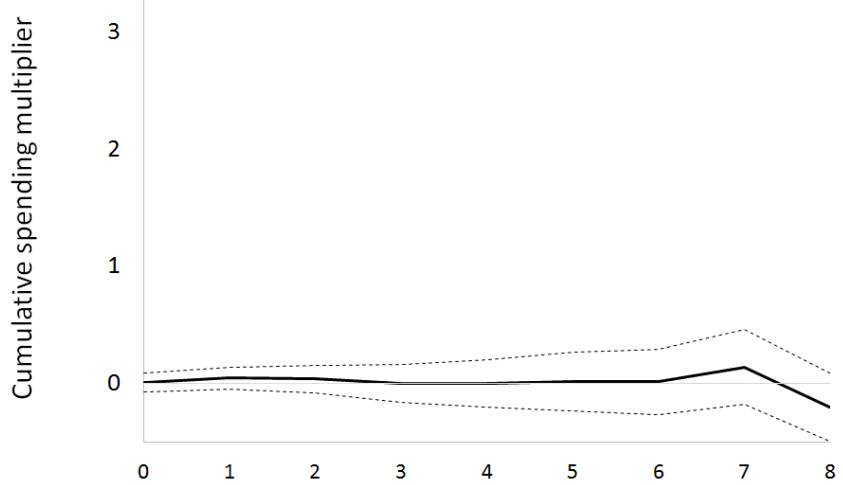

Quarter

Panel C. Effect on private investment, evaluated at high ratio of initial stock of public capital to GDP

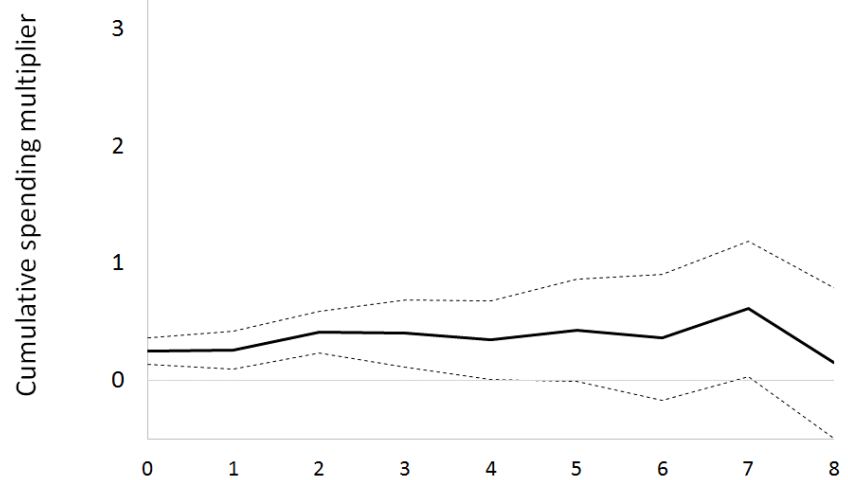

Quarter
Panel D. Effect on GDP, evaluated at low ratio of initial stock of public capital to GDP

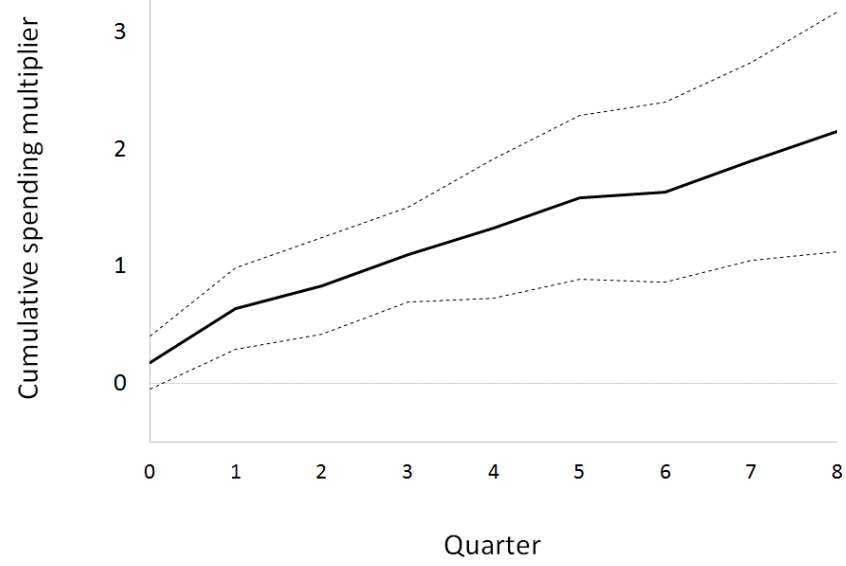

Panel E. Effect on private consumption, evaluated at ratio of initial stock of public capital to GDP

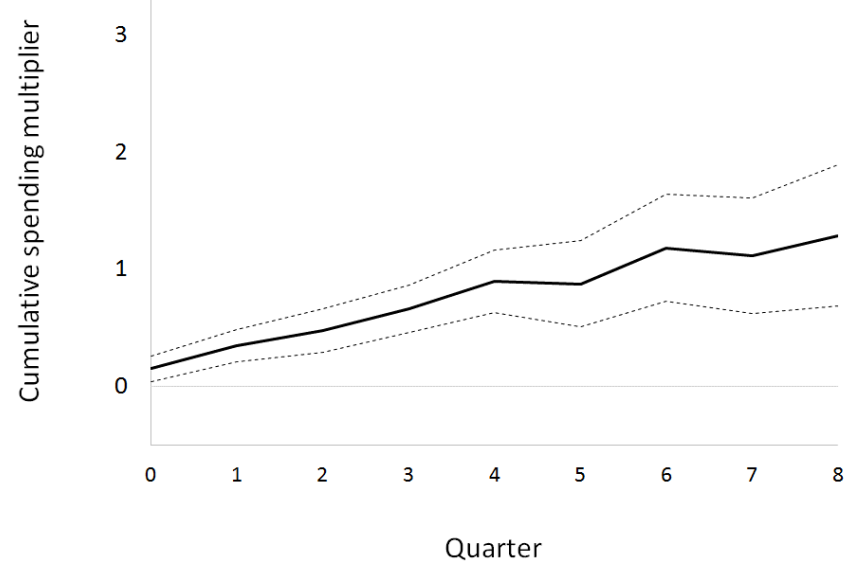

Panel F. Effect on private investment, evaluated at low ratio of initial stock of public capital to GDP

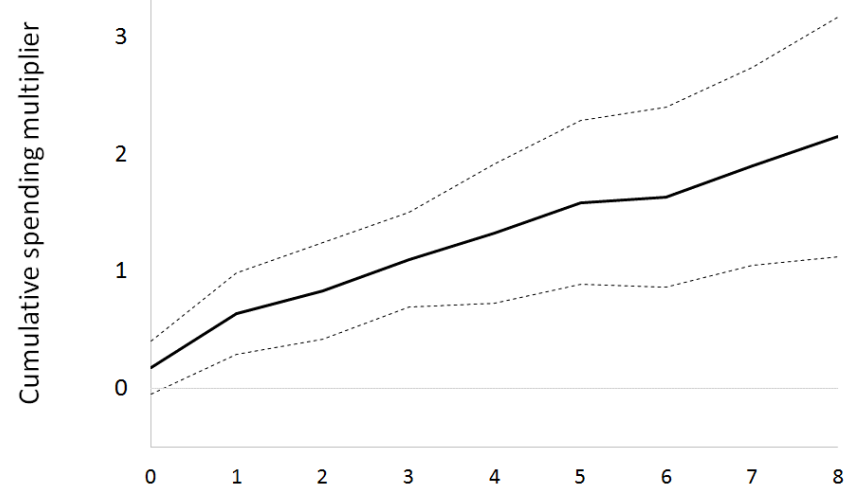

Quarter

Notes: Country fixed effect panel regression with linear and quadratic trends, standard errors are Driscoll-Kraay standard errors and bootstrapped. 
Figure 4. Public investment multiplier after two years of the spending shock evaluated at different ratio of initial stock of public capital to GDP:

Evidence from European countries

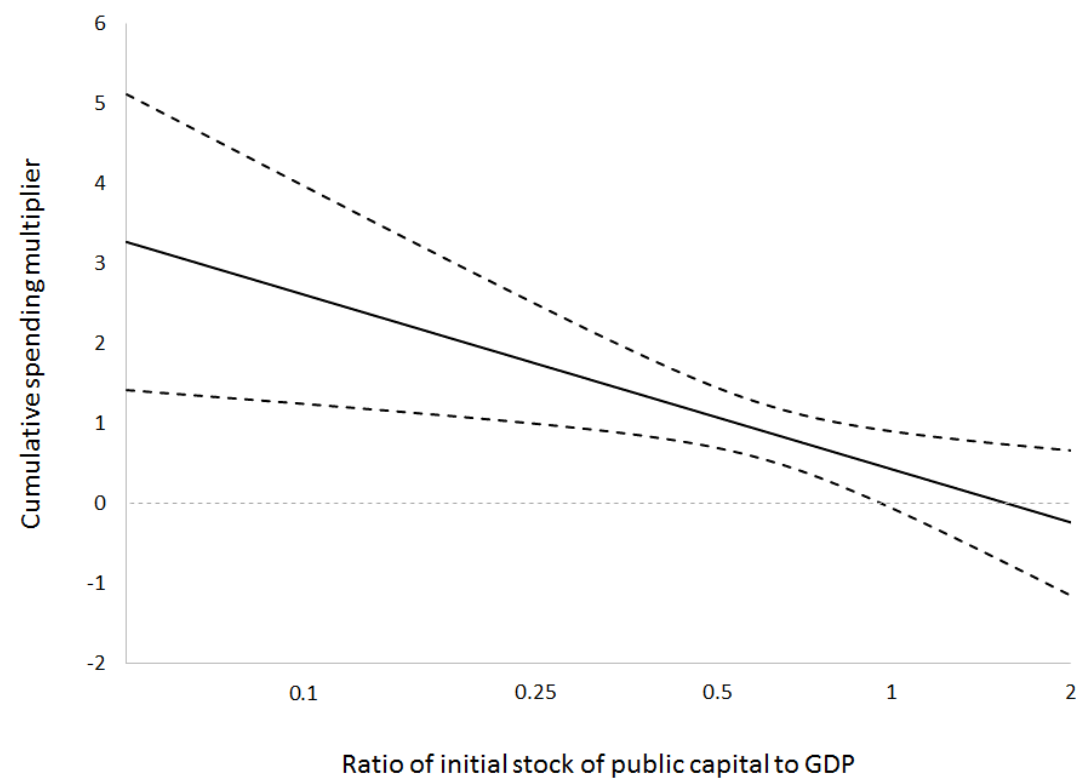

Notes: Country fixed effect panel regression with linear and quadratic trends, standard errors are DriscollKraay standard errors and bootstrapped. 
Figure 5. Public investment multiplier after two years of the spending shock: Evidence from European countries

Panel A. Evaluated at ratio of initial stock of public capital to GDP of 1990

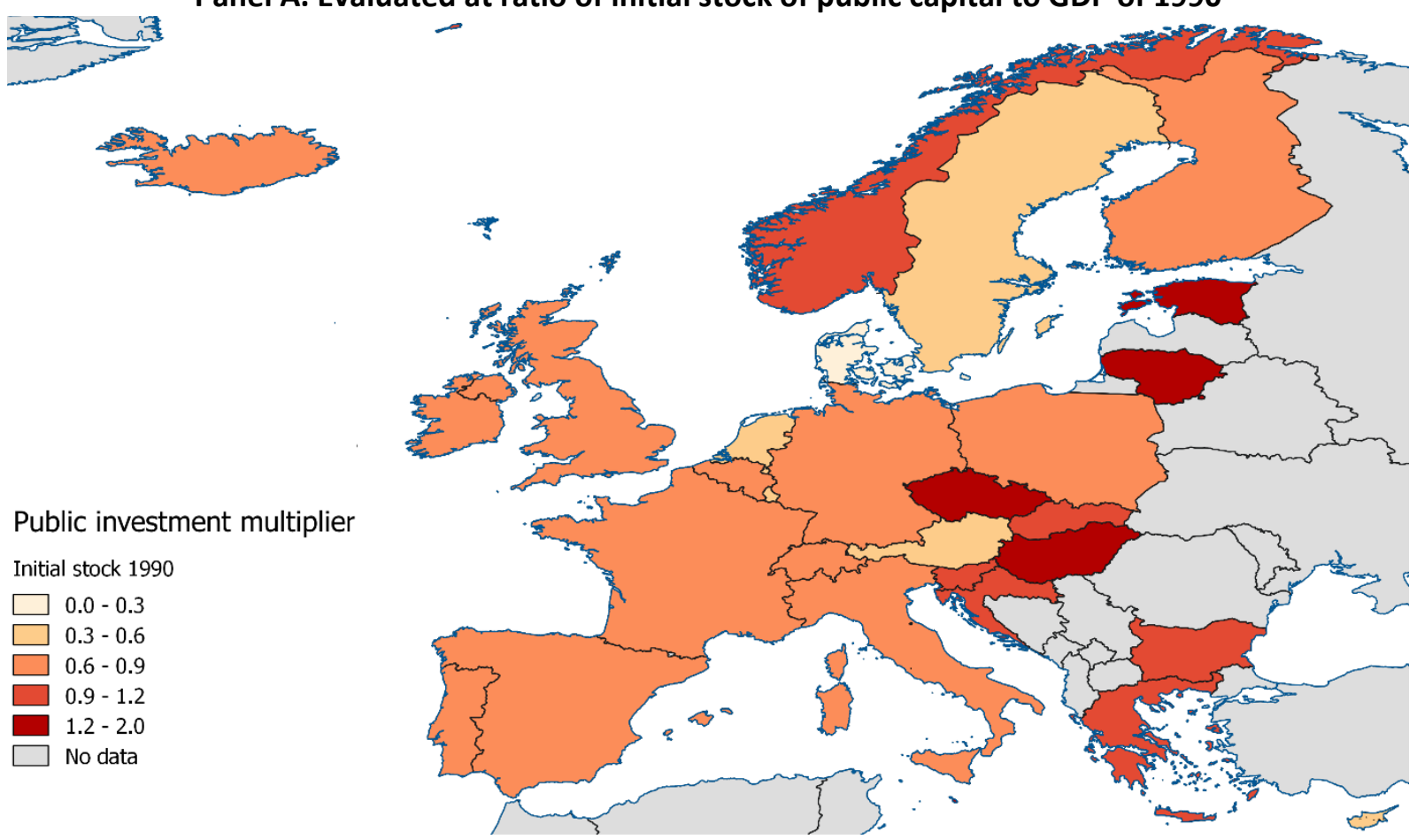

Panel B. Evaluated at ratio of initial stock of public capital to GDP of 2014
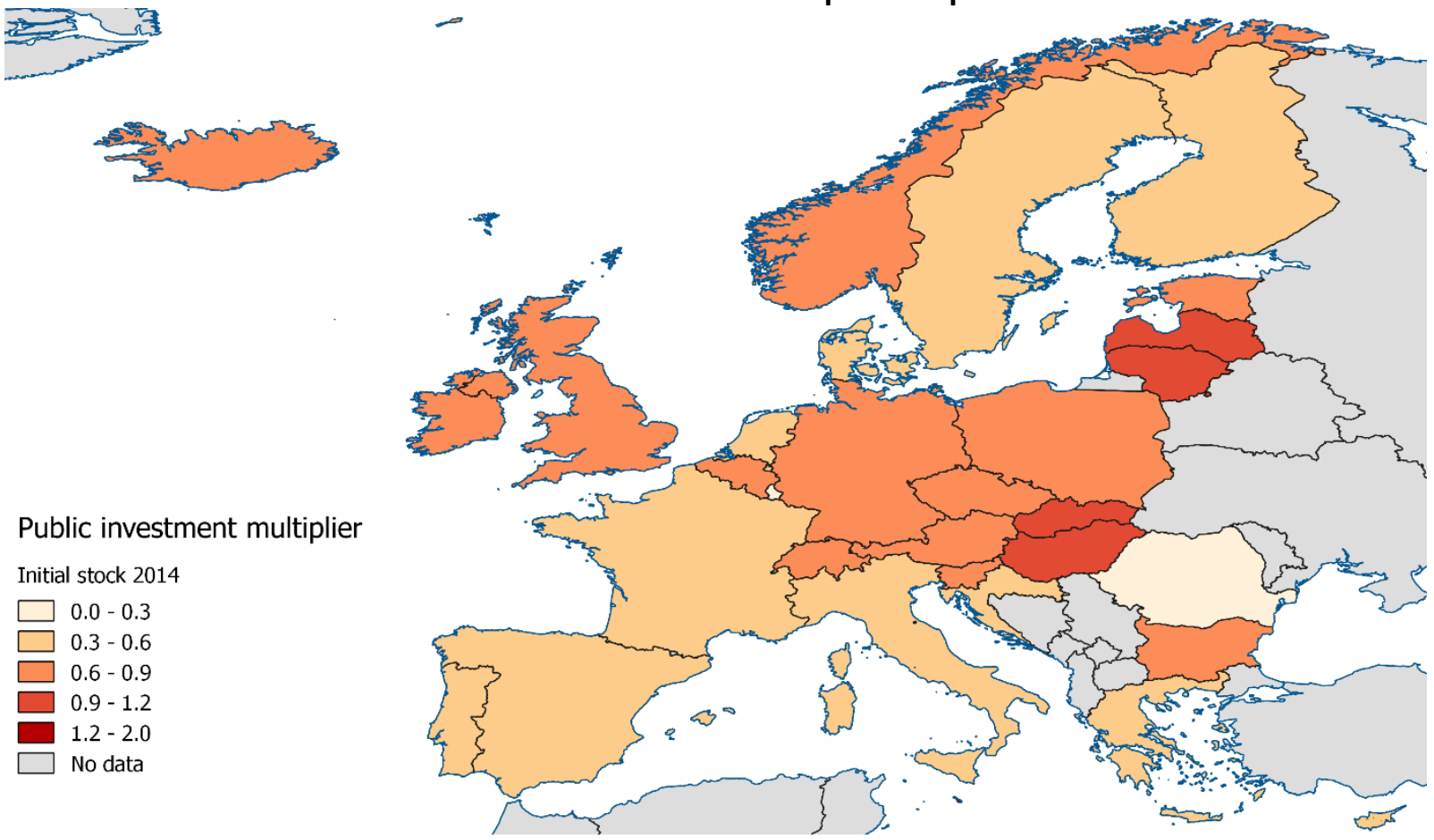

Public investment multiplier Initial stock 2014

$\square \quad 0.0-0.3$
$\square 0.3-0.6$
$\square 0.6-0.9$
$\square 0.9-1.2$
$\square 1.2-2.0$
$\square$ No data


Figure 6. Public investment multiplier after two years of the spending shock: Evidence from European countries

Panel A. Evaluated at different levels of efficiency

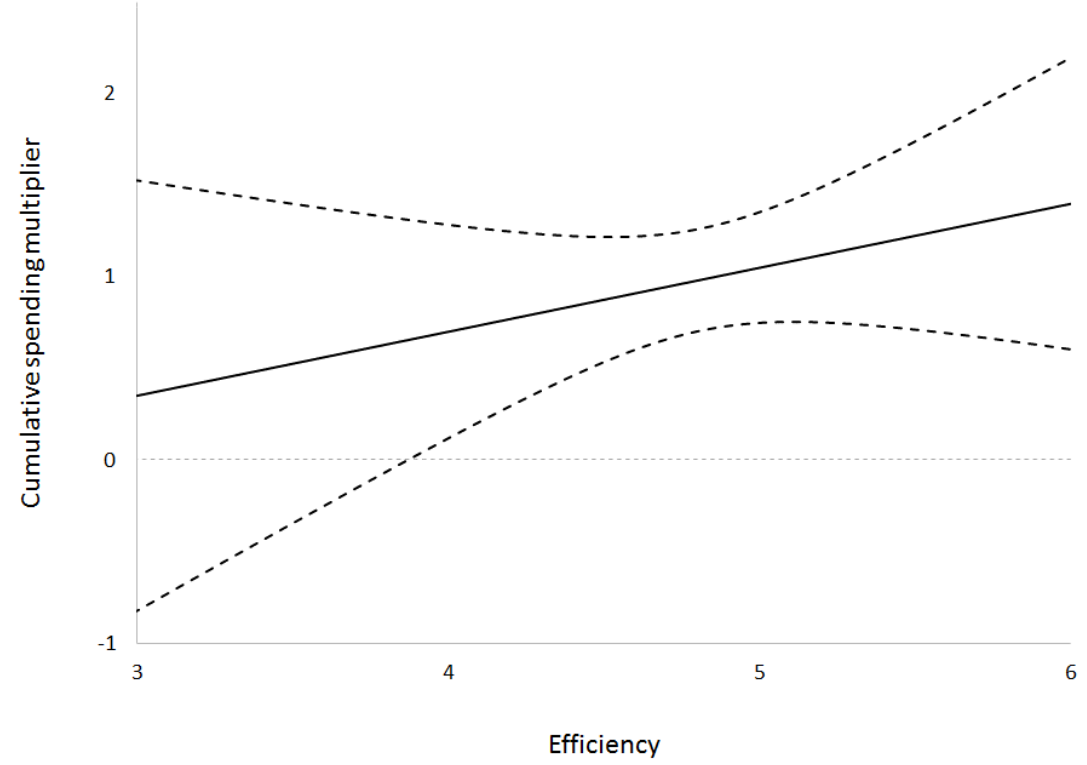

Panel B. Evaluated at different ratio of initial stock of public capital to GDP

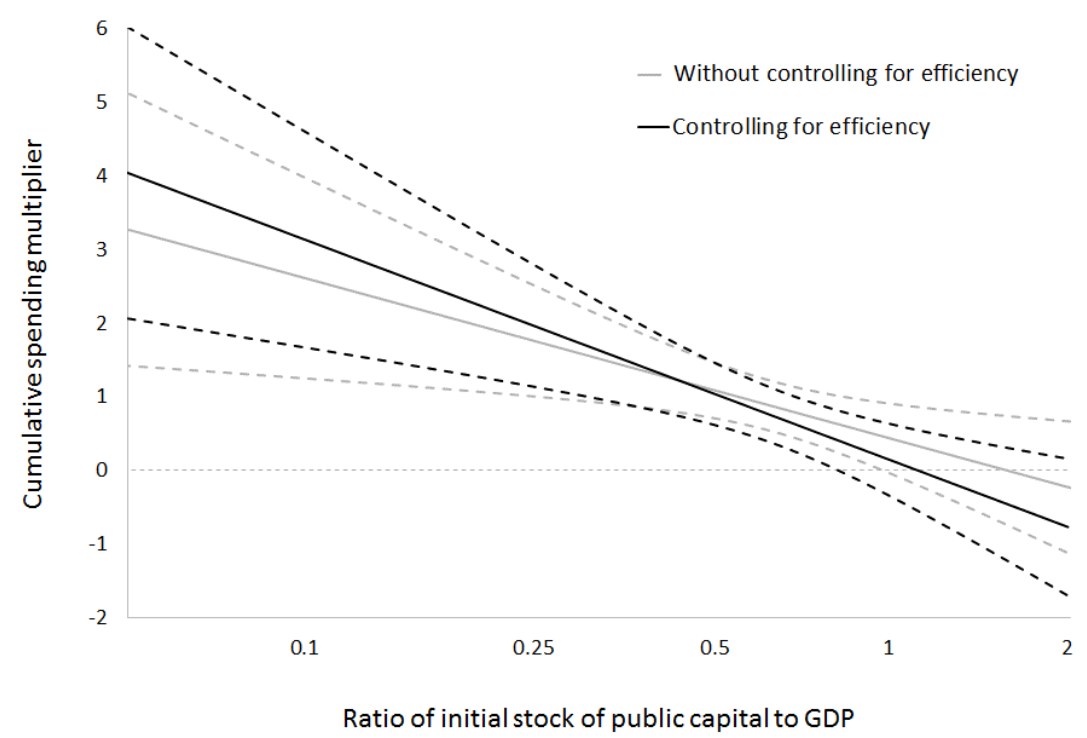

Notes: Country fixed effect panel regression with linear and quadratic trends, standard errors are DriscollKraay standard errors and bootstrapped. 
Figure 7. Primary spending and public investment multipliers:

Evidence from United State states

Public investment, conditional on high and low ratio of initial stock of public capital to GDP

2
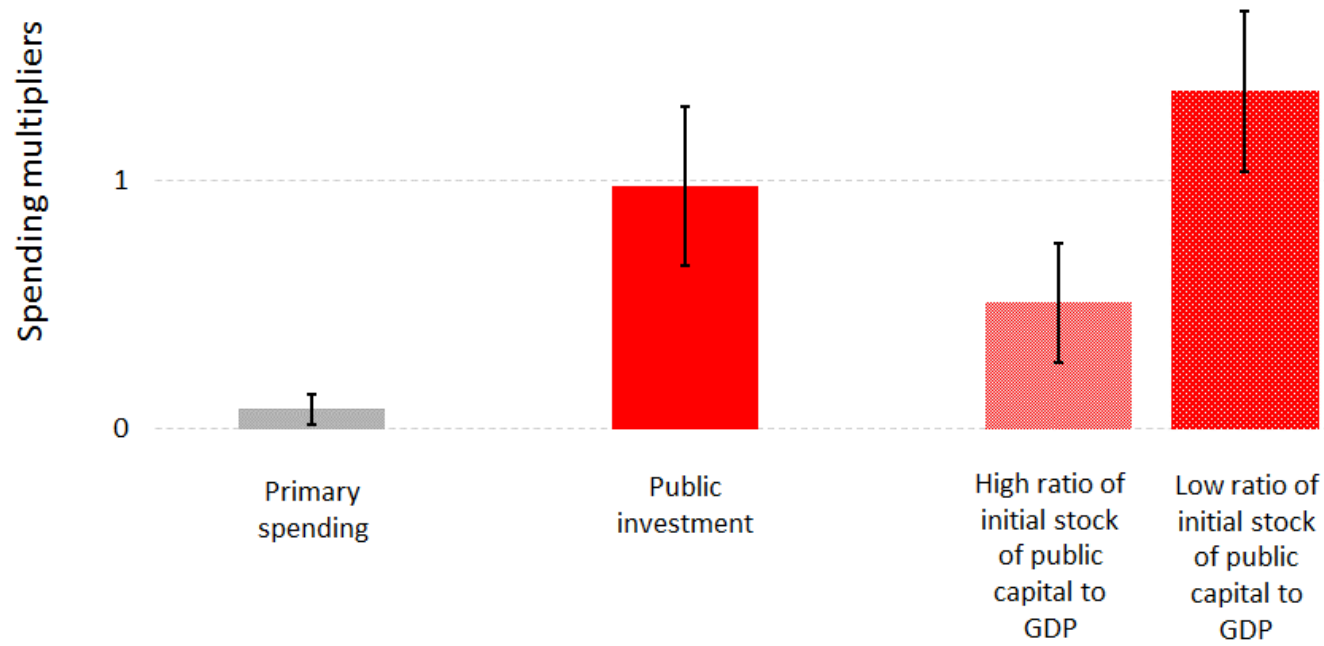

Note: The 5th percentile and 95th percentile is used to identify low and high ratio of initial stock of public capital to GDP in United State states, respectively. State fixed effect panel regression with linear and quadratic trends, standard errors are Driscoll-Kraay standard errors and bootstrapped.

Figure 8. Ratio of initial stock of public capital to GDP in U.S. states

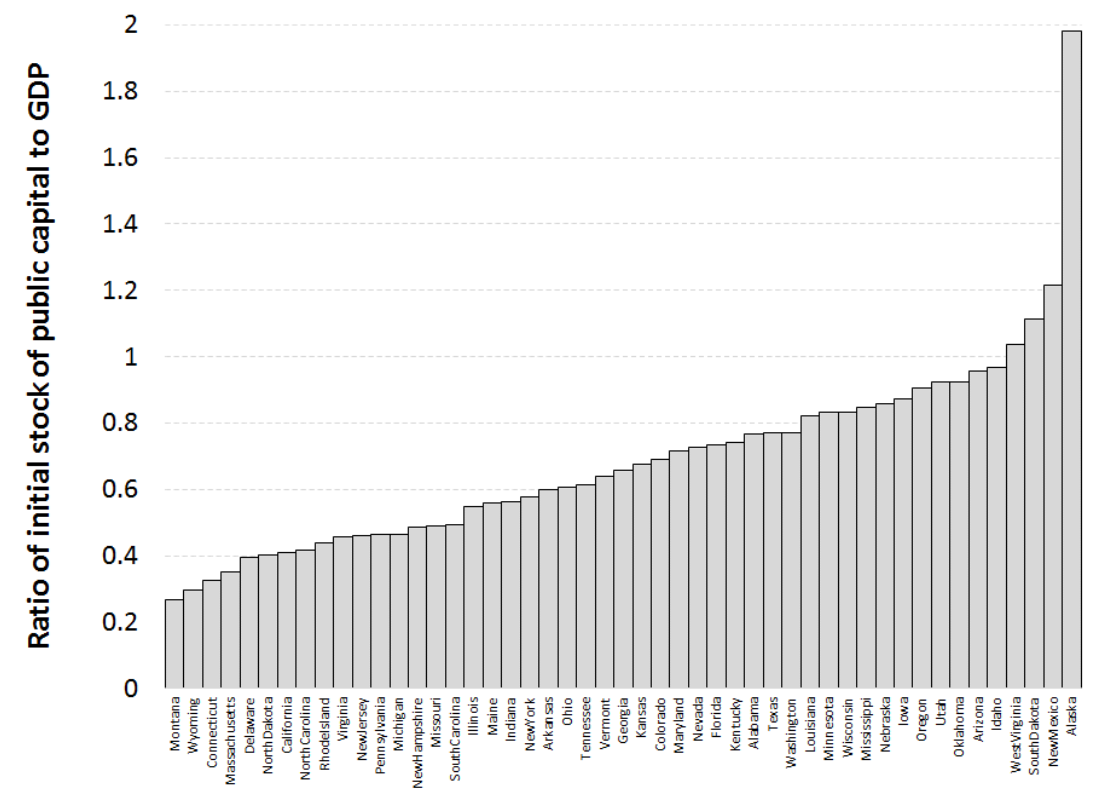


Figure 9. Public investment multiplier evaluated at different ratios of initial stock of public capital to GDP:

Evidence from United State states

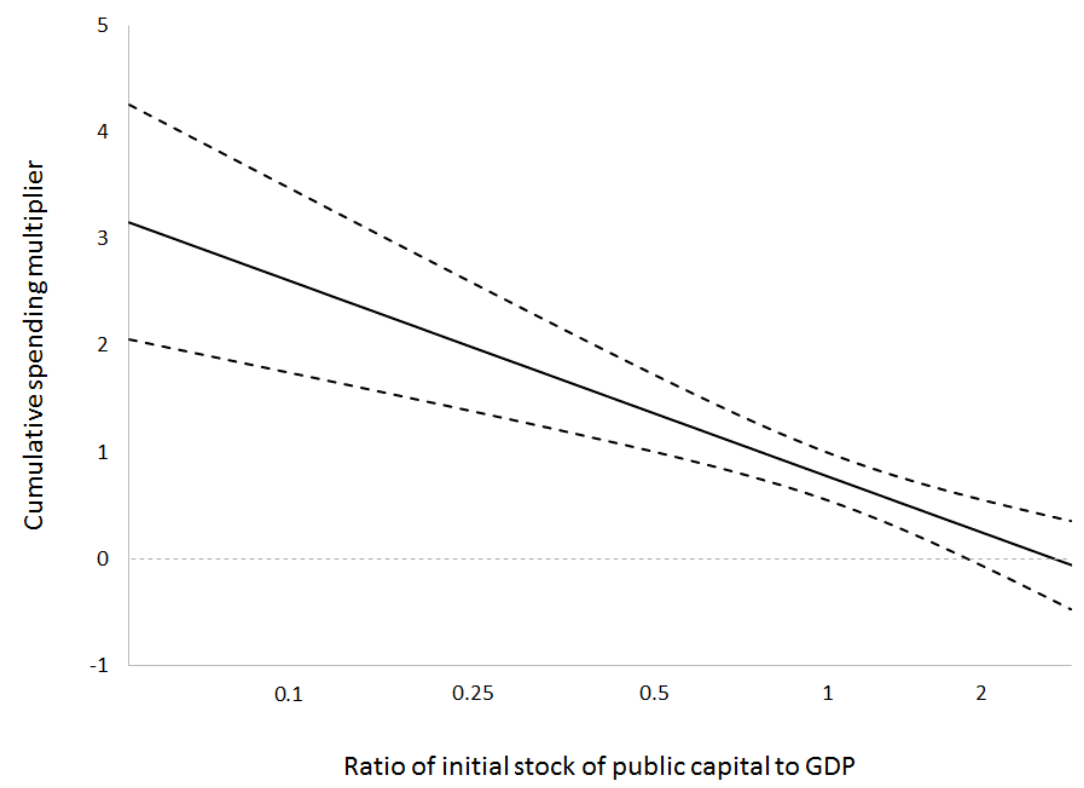

Notes: State fixed effect panel regression with linear and quadratic trends, standard errors are Driscoll-Kraay standard errors and bootstrapped. 
Figure 10. Public investment multiplier after two years of the spending shock: Evidence from United State states

Panel A. Evaluated at the average ratio of stock of public capital to GDP of 1980-1985

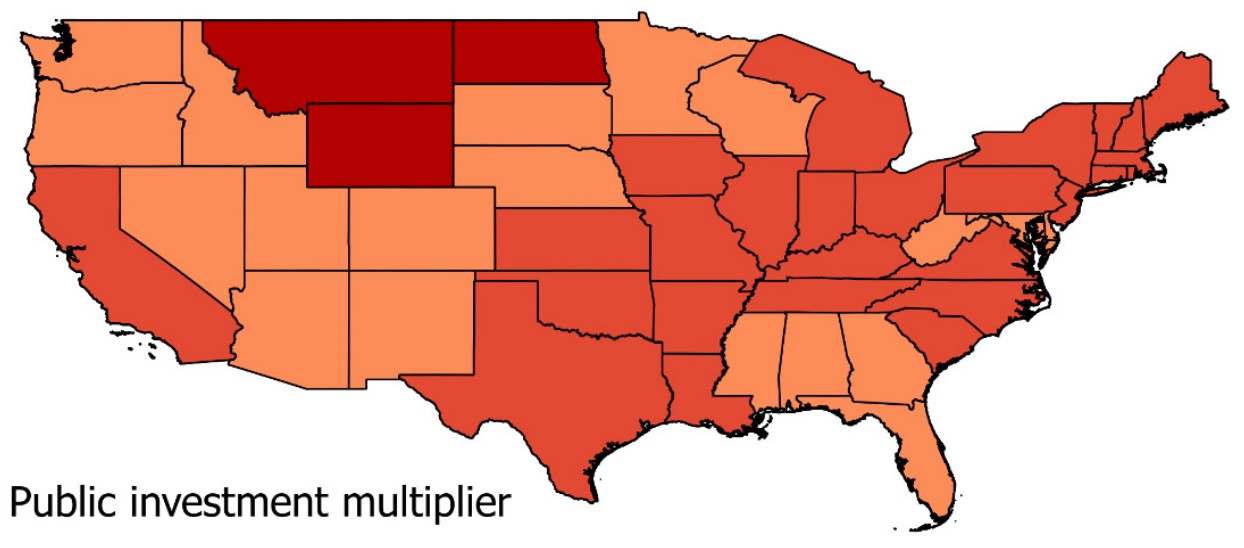

Initial stock 1980-1985 (average)
$0.0-0.3$
$0.3-0.6$
$0.6-0.9$
$0.9-1.2$
$1.2-2.0$
No data

Panel B. Evaluated at the average ratio of stock of public capital to GDP of 2012

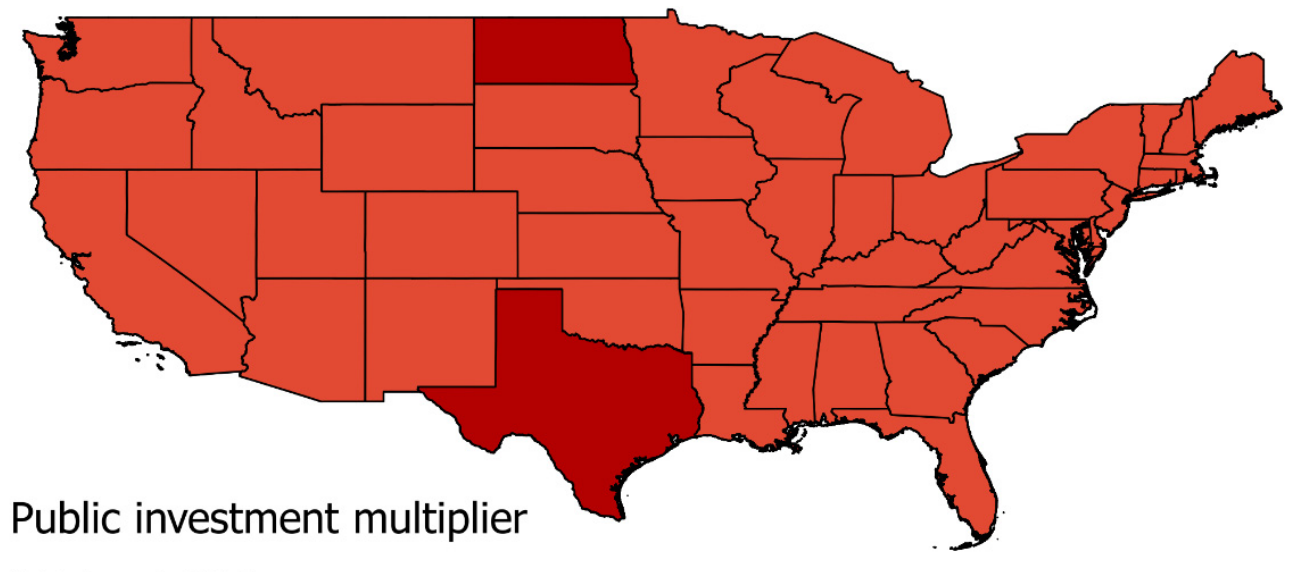

Initial stock 2012

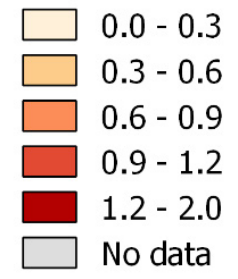


Figure 11. Key empirical factors behind the use of provincial over-representation in the Chamber of Deputies as instrument for provincial primary spending per capita

Panel A. Partial correlation between federal fiscal transfers per capita and provincial primary spending per capita

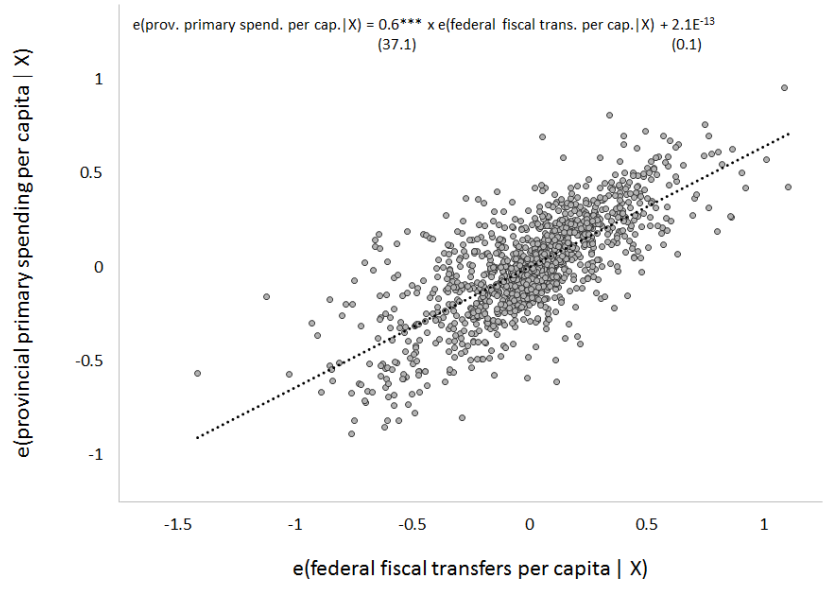

Panel B. Partial correlation between effective distortion in the Chamber of Deputies and federal fiscal transfers per capita

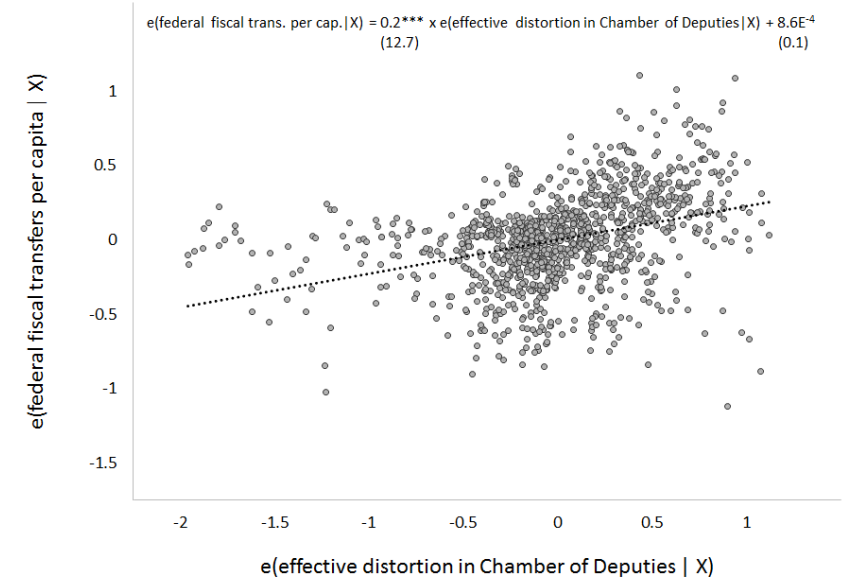

Panel C. Partial correlation between effective distortion in the Chamber of Deputies and provincial primary spending per capita

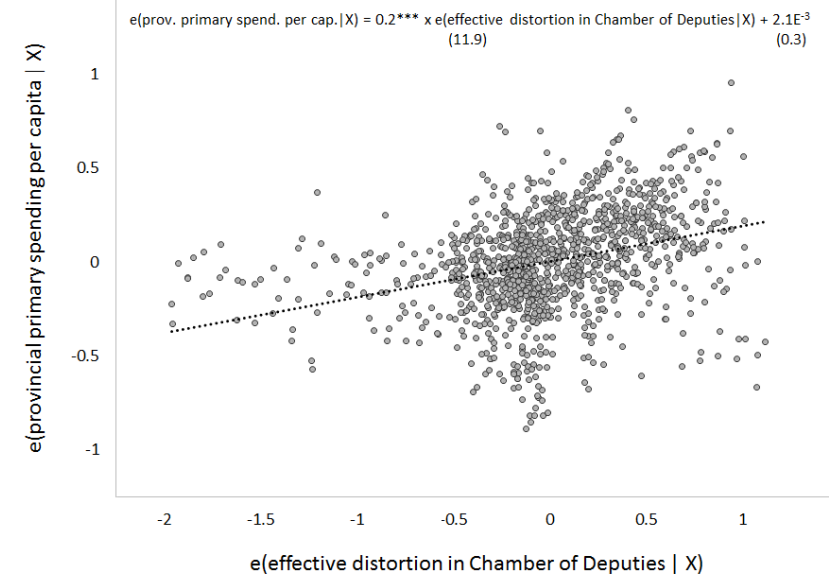

Notes: Each original variable is controlled for provincial fixed effect and linear and quadratic trends. Therefore, partial correlation graphs use respective residuals. T-statsitics are in brackets. 
Figure 12. Key empirical factors behind the use of provincial population dependency ratio as instrument for the proportion of provincial primary spending allocated to public investment and government consumption

Panel A. Partial correlation between provincial population dependency ratio and proportion of provincial primary spending allocated to public investment (1- $\theta)$

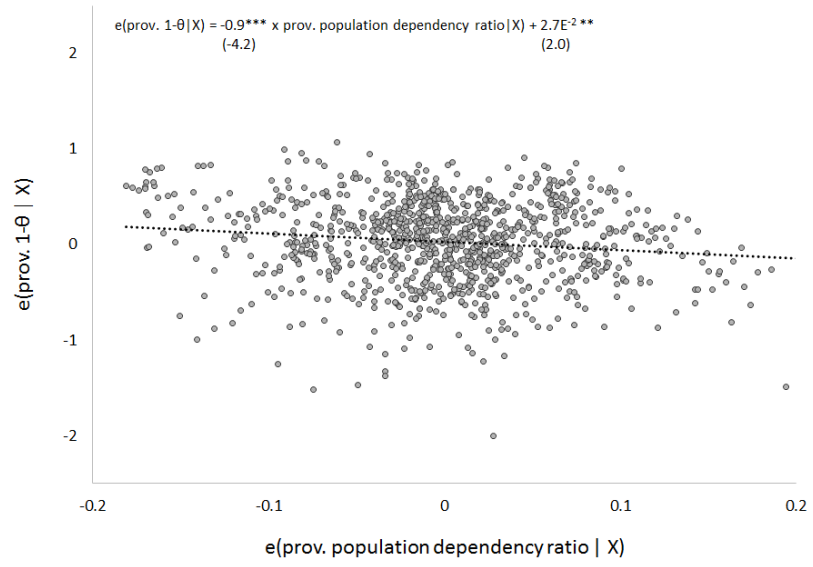

Panel B. Partial correlation between provincial population dependency ratio and proportion of provincial primary spending allocated to public consumption $\theta$

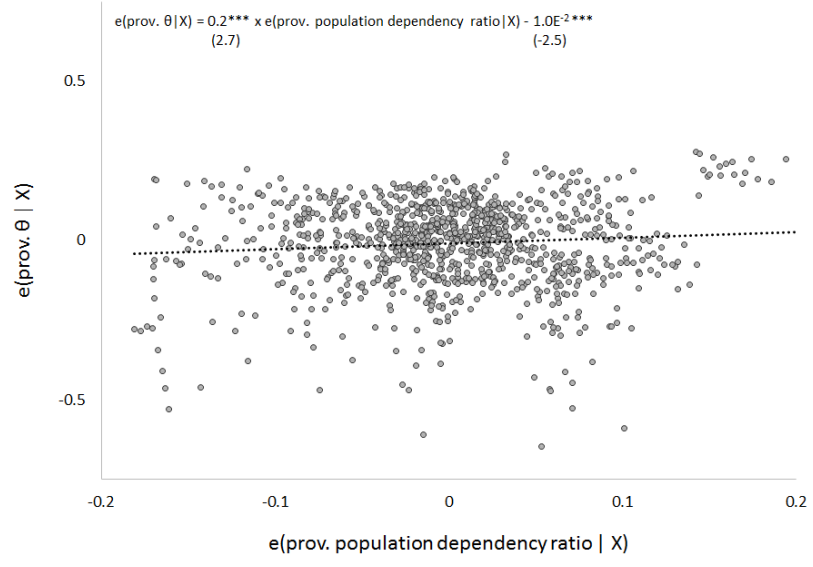

Panel C. Partial correlation between provincial population dependency ratio and provincial GDP growth

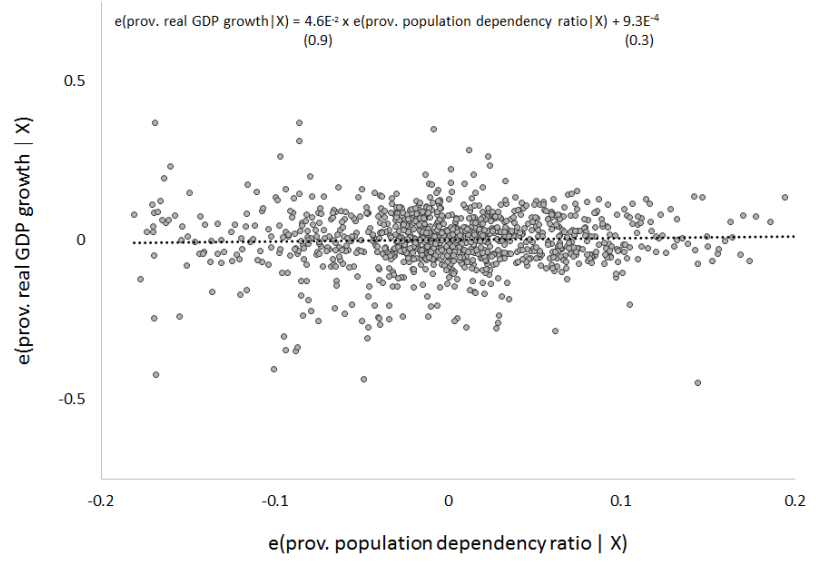

Panel D. Partial correlation between country population dependency ratio and proportion of country primary spending allocated to public investment (1- $\theta)$

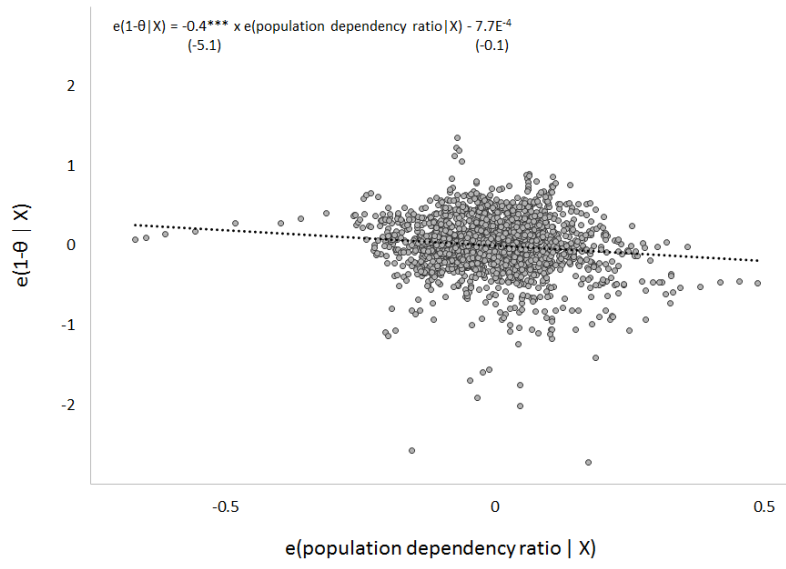

Panel E. Partial correlation between country population dependency ratio and proportion of country primary spending allocated to public consumption $\theta$

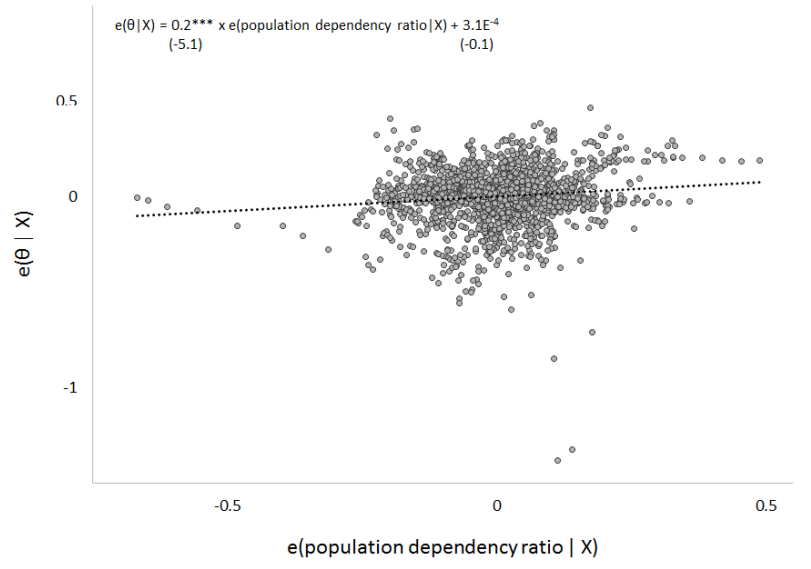

Panel F. Partial correlation between population dependency ratio and provincial GDP growth

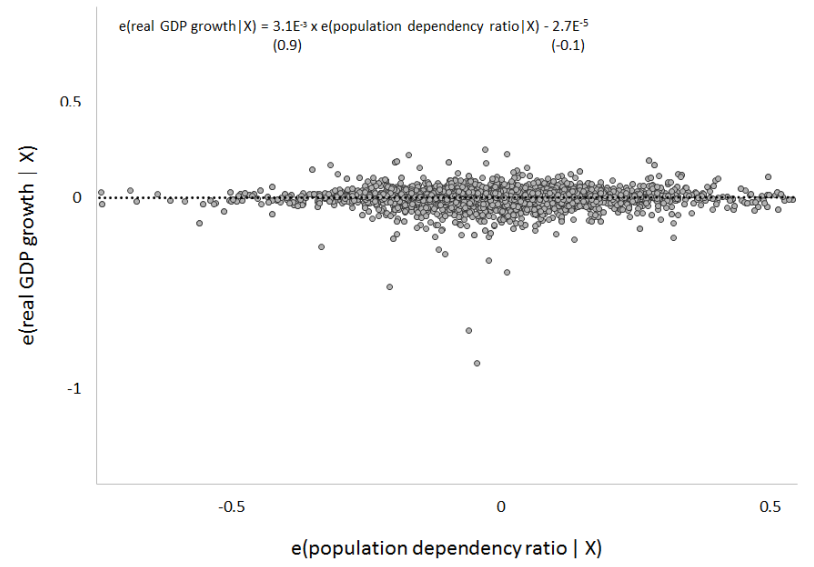

Notes: Each original variable is controlled for provincial (Panels A, B, and C) or country (Panels D, E, and F) fixed effect and linear and quadratic trends. Therefore, partial correlation graphs use respective residuals. T-statsitics are in brackets. 
Figure 13. Primary spending and public investment multipliers:

Evidence from Argentinean provinces

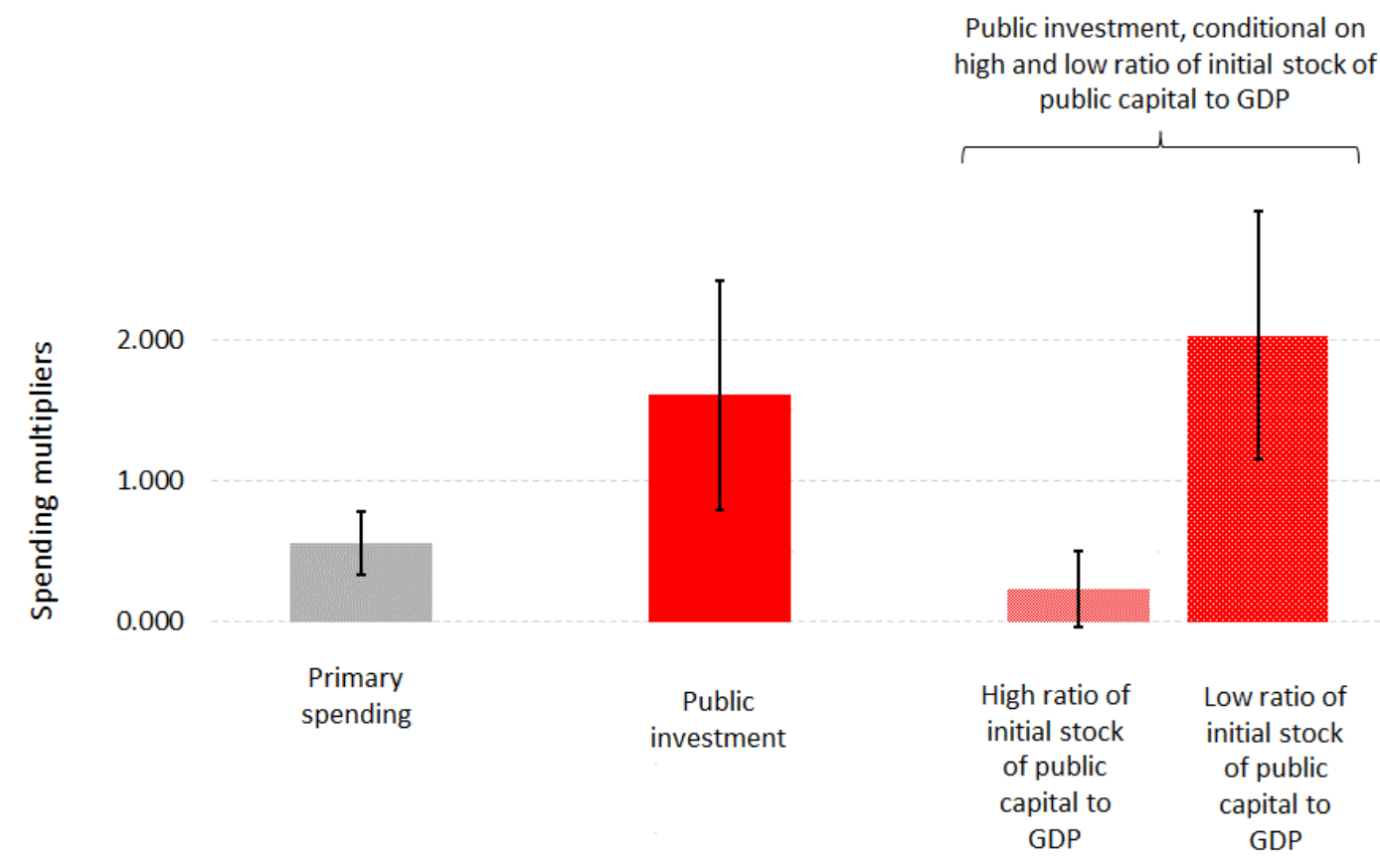

Note: The 5th percentile and 95th percentile is used to identify low and high ratio of initial stock of public capital to GDP in Argentinean provinces, respectively. Provincial fixed effect panel regression with linear and quadratic trends, standard errors are Driscoll-Kraay standard errors and bootstrapped.

Figure 14. Ratio of initial stock of public capital to GDP in Argentinean provinces

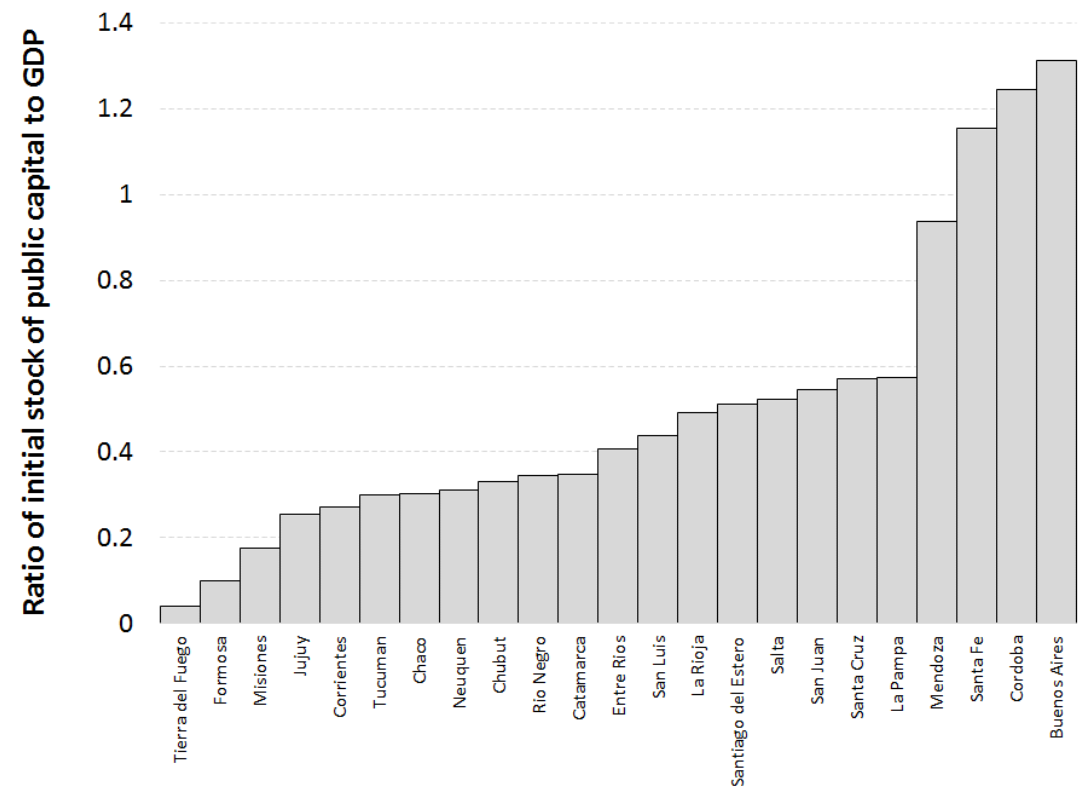


Figure 15. Public investment multiplier evaluated at different ratios of initial stock of public capital to GDP: Evidence from Argentinean provinces

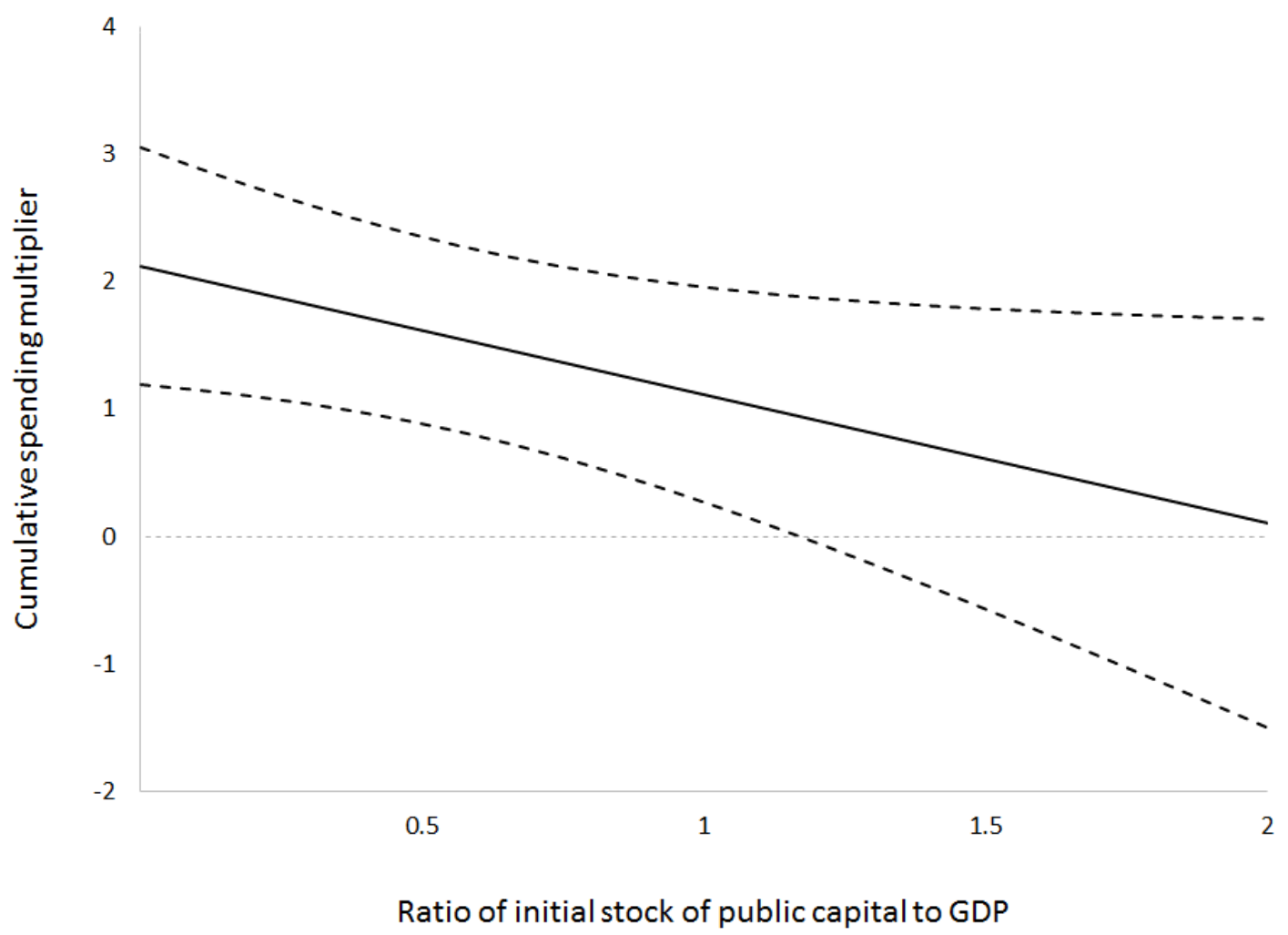

Notes: State fixed effect panel regression with linear and quadratic trends, standard errors are Driscoll-Kraay standard errors and bootstrapped. 


\section{Figure 16. Investment multiplier for Argentinean provinces}

Panel A. For the year 1964

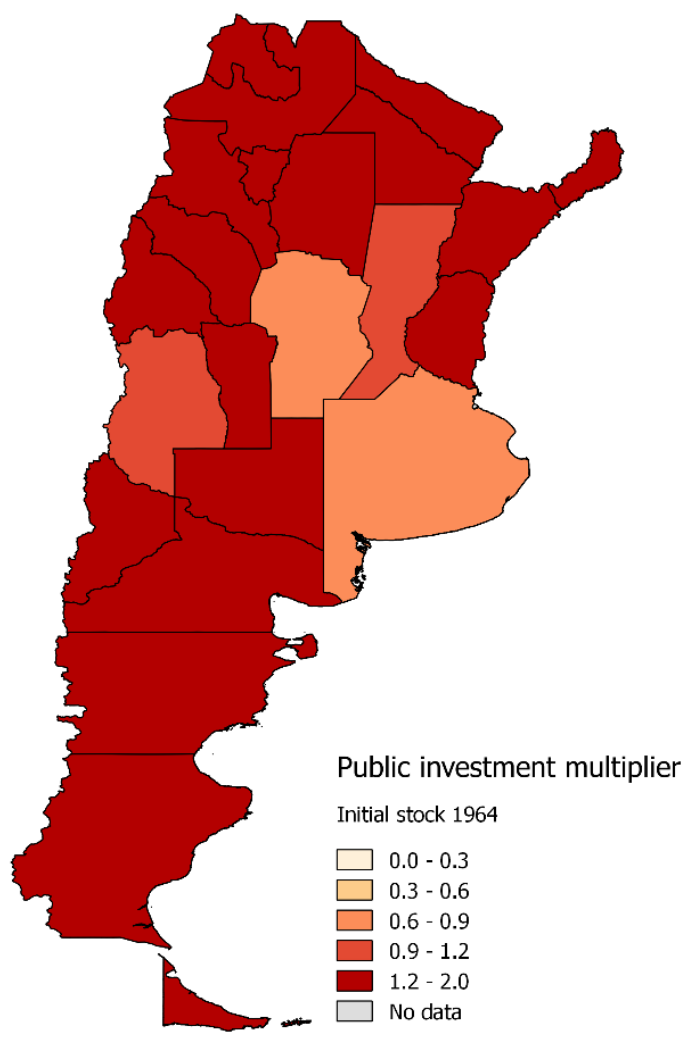

Panel B. For the year 1990

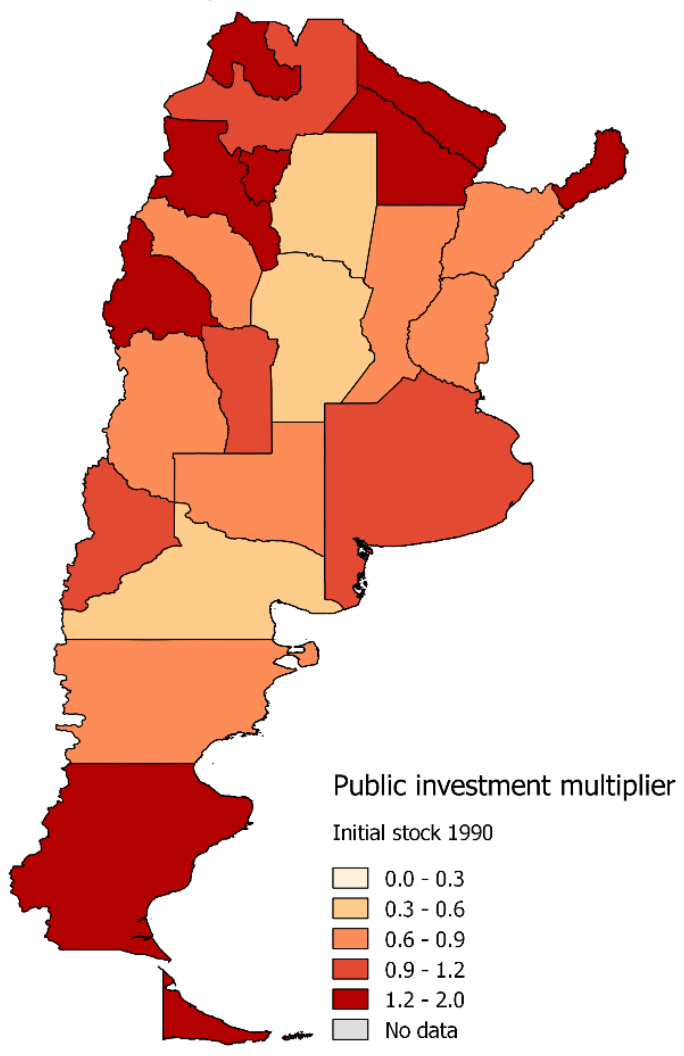

Panel C. For the year 2014

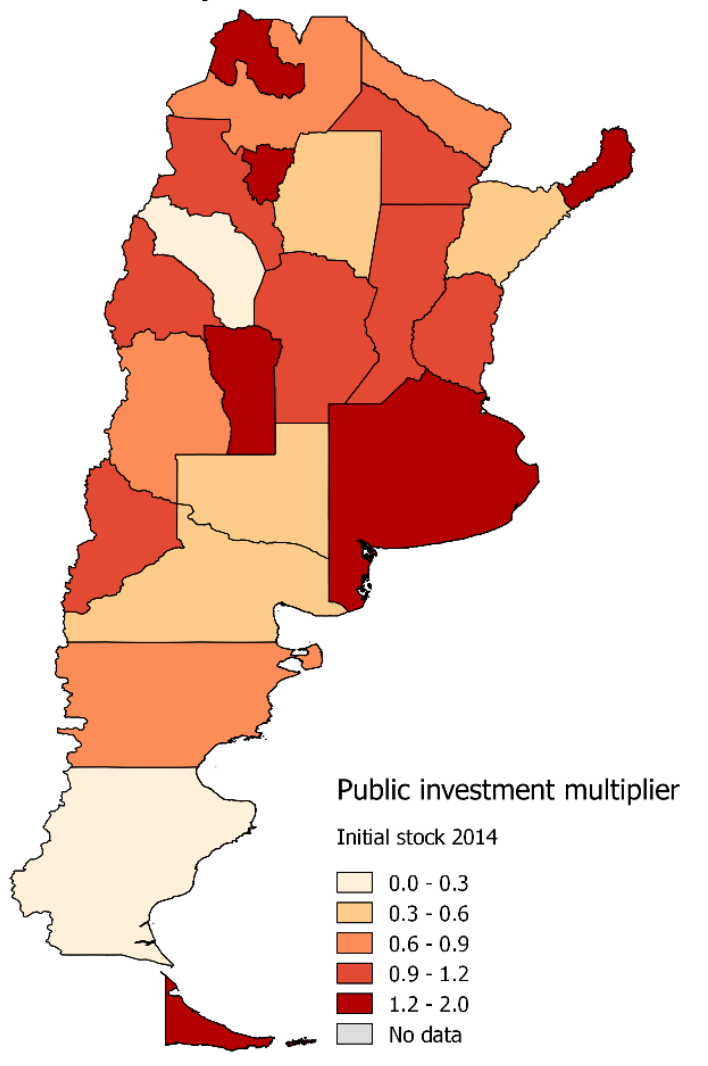


Figure 17. Comparison of our public investment multiplier based on a non-linear strategy with public investment multiplier from external sources for 17 countries.

\section{Panel A. Vis-à-vis comparison for each country}

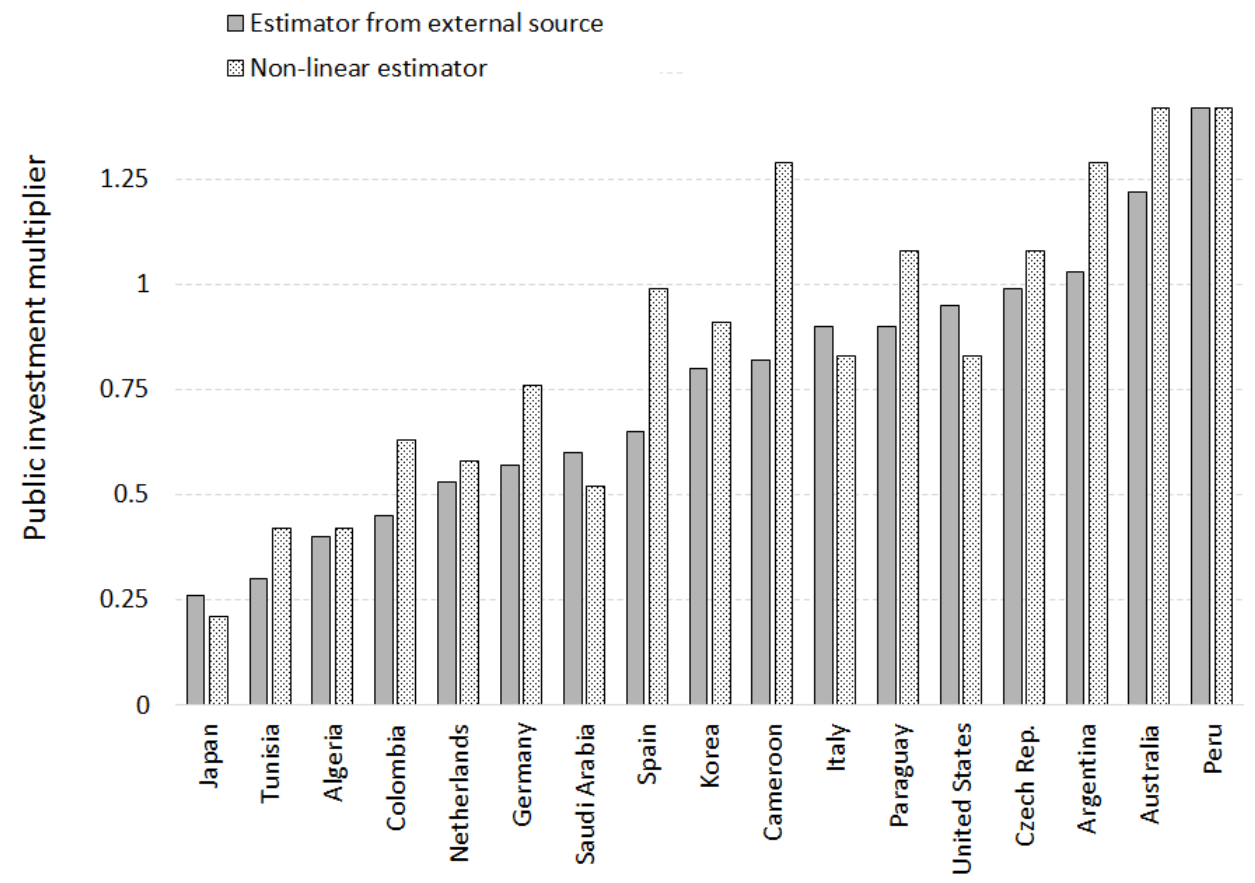

Panel B. Regression between our public investment multiplier based on a non-linear strategy and public investment multiplier from external sources

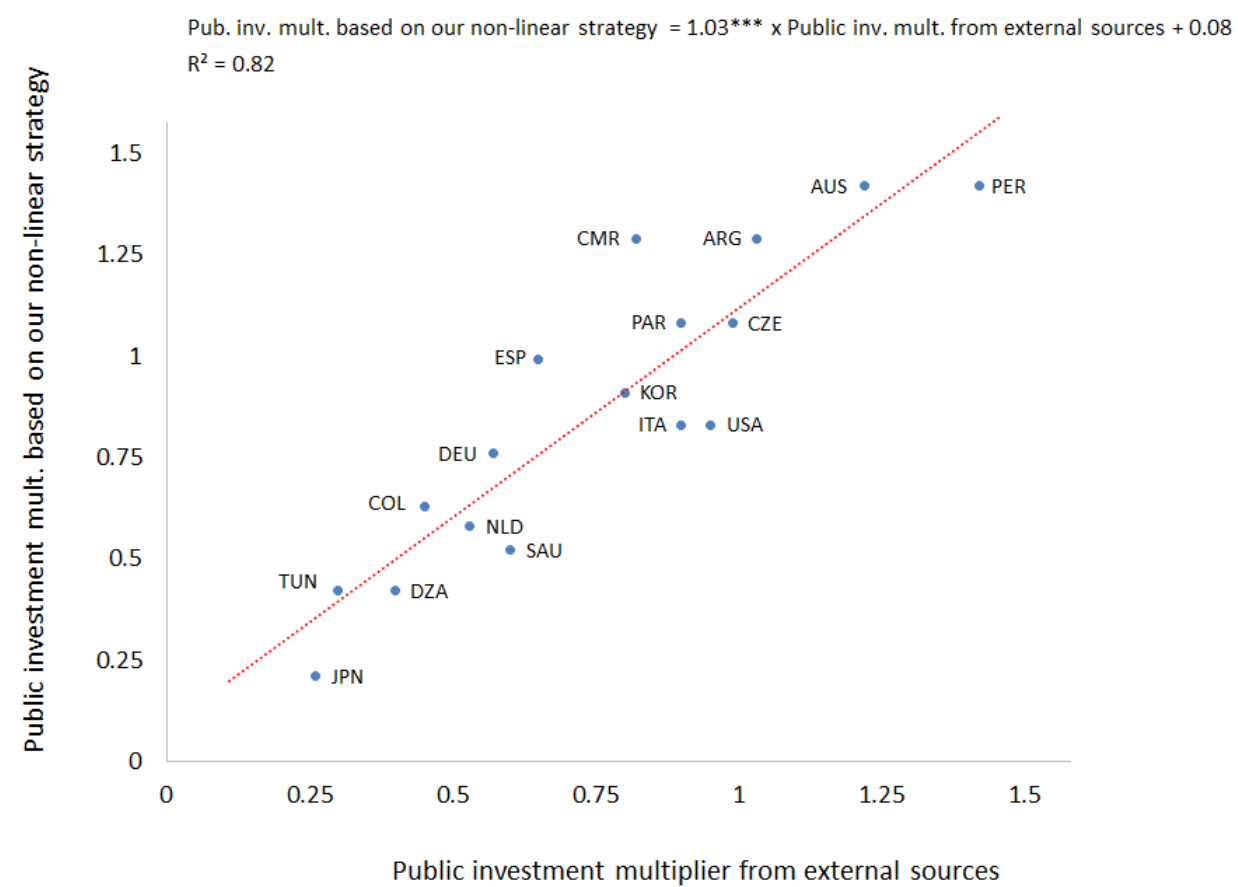

Notes: See Appendix 2 for details. 